\title{
Left ventricular summit - concept, anatomical description and clinical significance
}

\author{
Marcin Kuniewicz ${ }^{1}$, Artur Baszko ${ }^{2}$, Mateusz Holda ${ }^{1}$, Dyjhana Ali ${ }^{1}$, Grzegorz Karkowski ${ }^{3}$, \\ and Jerzy Walocha ${ }^{1}$ \\ ${ }^{1}$ Jagiellonian University Medical College \\ ${ }^{2}$ Poznan University of Medical Sciences \\ ${ }^{3}$ Jagiellonian University Medical College Institute of Cardiology
}

August 9, 2021

\begin{abstract}
The left ventricular summit (LVS) is a triangular area located at the most superior portion of the left epicardial ventricular region, surrounded by the two branches of the left coronary artery: the left anterior interventricular artery and the left circumflex artery. The triangle is bounded by the apex, septal and mitral margins and base. This review aims to provide a systematic and comprehensive anatomical description and proper terminology in the LVS region that may facilitate exchanging information among anatomists and electrophysiologists, increasing knowledge of this cardiac region. We postulate that the most dominant septal perforator (not the first septal perforator) should characterize the LVS definition. Abundant epicardial adipose tissue overlying the LVS myocardium may affect arrhythmogenic processes and electrophysiological procedures within the LVS region. The LVS is divided into two clinically significant regions: accessible and inaccessible areas. Rich arterial and venous coronary vasculature and a relatively dense network of cardiac autonomic nerve fibers are present within the LVS boundaries. Although the approach to the LVS may be challenging, it can be executed indirectly using the surrounding structures. Delivery of the proper radiofrequency energy to the arrhythmia source, avoiding coronary artery damage at the same time, may be a challenge. Therefore, coronary angiography or cardiac computed tomography imaging is strongly recommended before any procedure within the LVS region. Further research on LVS morphology and physiology should increase the safety and effectiveness of invasive electrophysiological procedures performed within this region of the human heart.
\end{abstract}

Published in Diagnostics:

https://doi.org/10.3390/diagnostics11081423

\section{Introduction}

Despite the intensive research in the anatomical sciences for the past couple of centuries, some structures within the body remain incompletely described [1-3]. Moreover, recent developments in invasive cardiology and electrophysiology have renewed interest in detailed cardiac anatomy $[4,5]$. One of the structures that are currently of special interest is the left ventricular summit (LVS). The LVS is defined as a triangular epicardial area located at the bifurcation of the left coronary artery. Recent studies are reemphasizing the importance of LVS as the source of ventricular arrhythmias with a high level of difficulty for treatment with radiofrequency ablation [6]. There are various approaches for reaching LVS arrhythmias.

Nevertheless, the proximity of the surrounding major cardiac structures might pose a risk of complications, and therefore, ablation within the LVS region may be challenging [7]. Important anatomical structures, such as surrounding coronary arteries, epicardial fat and fibrotic components, may complicate the approach [8]. Therefore, this review aims to give an extensive review of the anatomical terminology and procedural knowledge of LVS that may improve the understanding of this heart region to facilitate the performance of the radiofrequency ablation procedures.

LVS definition and anatomy 
The LVS is a triangular area located at the most superior portion of the left epicardial ventricular region, surrounded by the two branches of the left coronary artery: the left anterior interventricular artery and the left circumflex artery [9]. The triangle is bounded by septal and mitral margins (Figure 1). A delineation by an arched line, with the radius of this arc being the distance from the left coronary bifurcation artery to the first prominent left coronary artery septal perforator, represents the most inferior boundary of this arc region (triangle base). Inside this triangular area, the anterior interventricular cardiac vein (that travels through the anterior part of the atrioventricular groove) becomes the great cardiac vein that is further heading to the posterior part of the atrioventricular groove [10-14]. Thus, the great cardiac vein/anterior interventricular cardiac vein bisects the LVS into two distinct areas: superior area (also named the inaccessible area for radiofrequency ablation because of the significant risk of coronary vasculature damage) and inferior area (the accessible area for radiofrequency ablation, where the interventions are relatively safe) (Figure 1A) [7]. Each part of the LVS has a specific relation to the adjacent anatomical structures, and each will be described below (Figure 1).

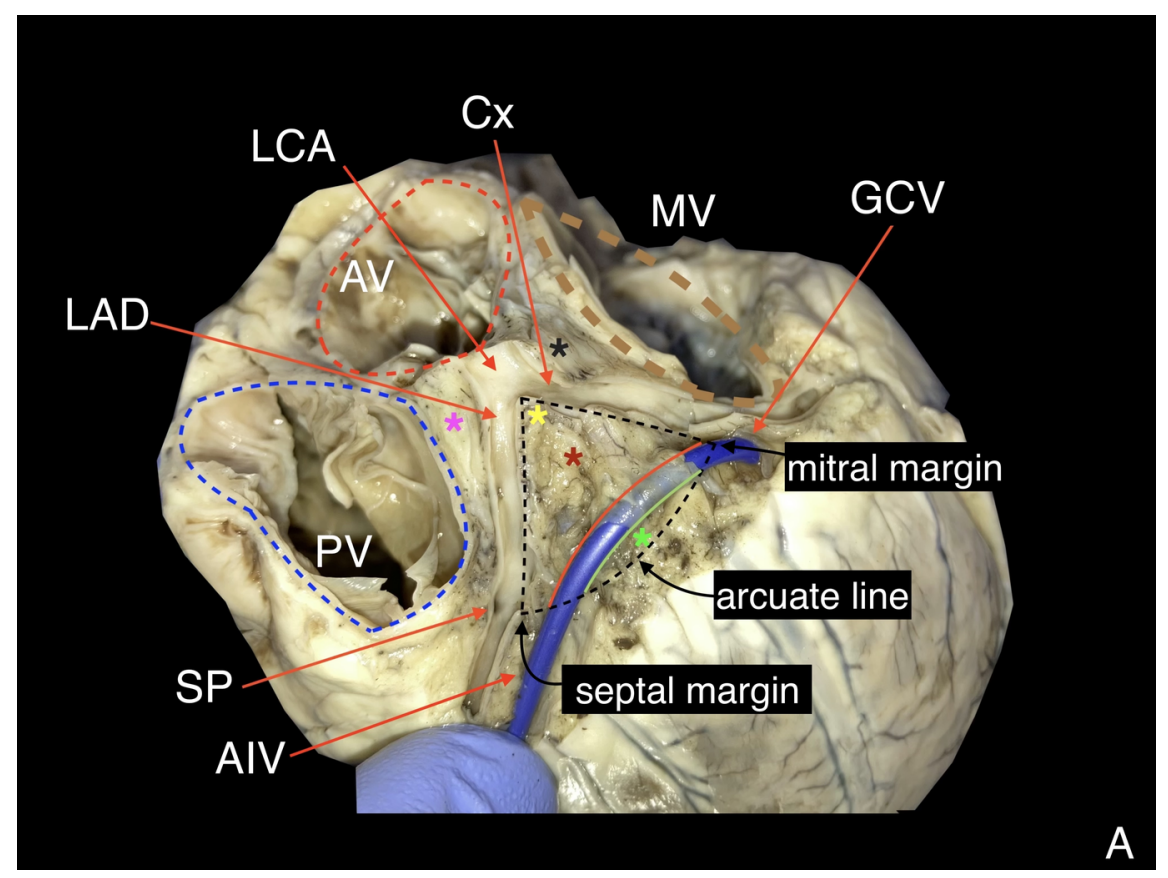




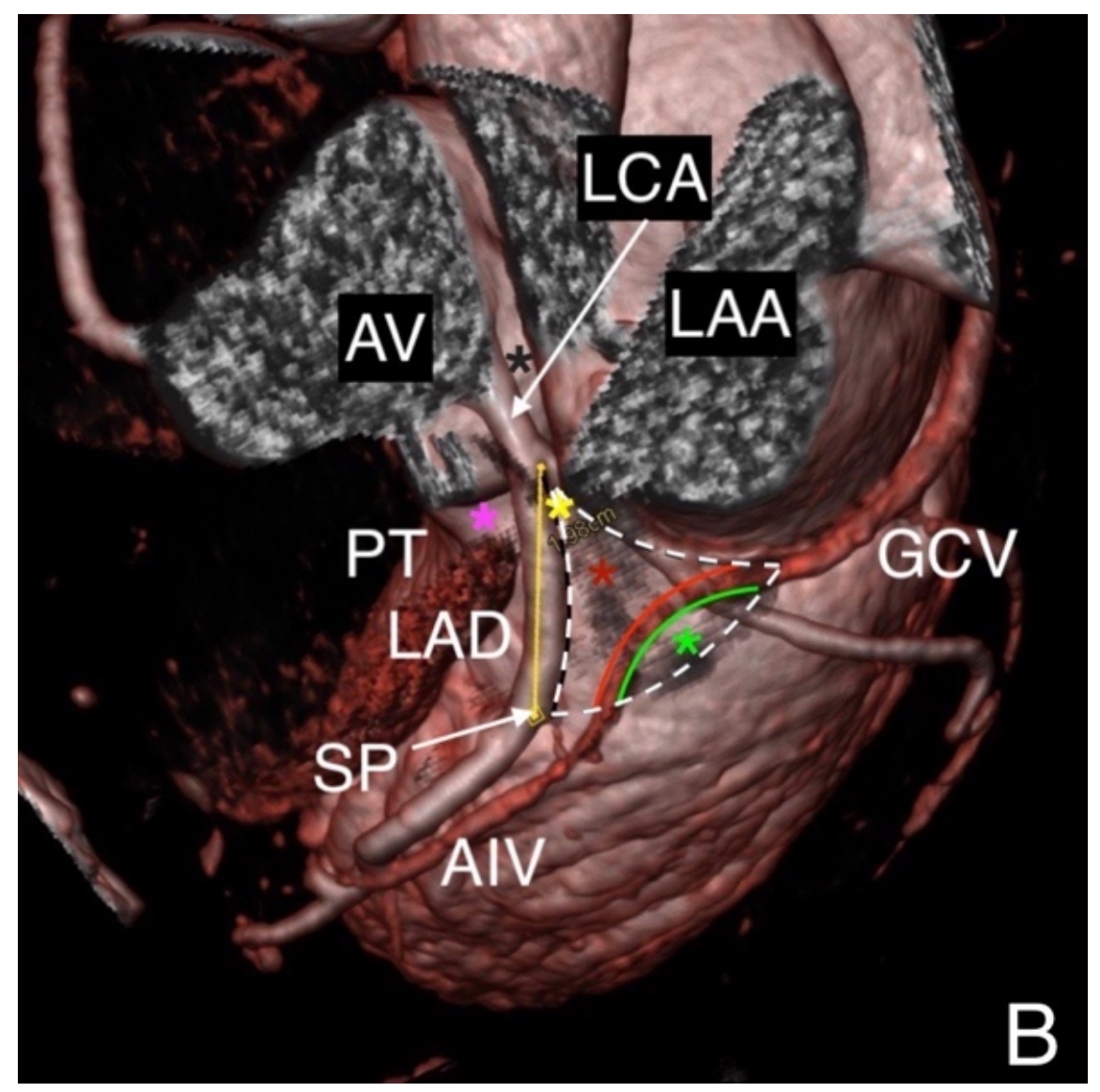

Figure $1 \mathrm{~A}$ - left ventricular summit in gross dissection at the level of the fibrous skeleton of the heart, B LVS in an angio-CT rendered image. Abbreviations: LVS = left ventricular summit; LAD = left anterior descending artery; LCA - left coronary artery; $\mathrm{Cx}=$ circumflex branch of left coronary artery; $\mathrm{GCV}=$ great cardiac vein; $\mathrm{AIV}=$ anterior interventricular vein; $\mathrm{SP}=$ septal perforator; $\mathrm{LAA}=$ left atrial appendage; $\mathrm{PT}$ = pulmonary trunk, $\mathrm{PV}$ pulmonary valve, $\mathrm{MV}$ - mitral valve, $\mathrm{AV}$ - aortic valve. red asterisk - inaccessible area; green asterisk accessible area; violet asterisk - septal summit; black asterisk - aortiomitral continuity; yellow asterisk - apex of LVS.

\section{LVS apex}

The apex of the LVS is located superiorly towards the left coronary arterial ostium. It begins at the left coronary artery's bifurcation to the left circumflex coronary artery and left anterior descending artery. The nearest neighboring structure to the LVS apex is the aortic root, covered by a large fibrous structure-the aorto-ventricular membrane [9] (Figure 2A). The aortic root is the continuation of the left ventricle outflow tract. It occupies a central position within the heart, located to the right and posteriorly, relative to the subpulmonary infundibulum [7]. The apex into the deep of the myocardium correlates with the left aortic sinus of Valsalva, septal summit to the right and aortic-mitral continuity to the left (Figure 1). The epicardial adipose tissue and pulmonary trunk cover the LVS apex (Figure 2A). The mean distance from the LVS apex to the aortic sinus origin of the left coronary artery is approximately $10 \mathrm{~mm}$, but may even reach $21 \mathrm{~mm}$ $[15,16]$. In approximately $10 \%$ of hearts, the left coronary artery trifurcates. Its third branch, the ramus intermedius, penetrates the LVS area, trespassing in the midsection over the accessible and inaccessible areas. In almost $2 \%$ of cases, the apex of the LVS cannot be defined because of the absence of the circumflex branch of the left coronary artery since it originates directly from the left sinus of Valsalva. In patients with 
bicuspid aortic valves, variants are even more commonly observed [16].

\section{Right margin of LVS - septal margin}

The anterior interventricular groove with the adjacent structures - the left anterior descending artery and anterior interventricular vein-determines the septal (or superior) boundary of the LVS $[8,17,18]$. The relationship between those two vessels in the majority $(54.4 \%)$ of cases presents a profound intersection of the anterior interventricular vein to the left anterior descending artery [19]. Along the artery and vein, the left coronary cardiac nerve forms the left coronary subplexus that contributes to the autonomic innervation of the left ventricle [20]. The septal margin corresponds with the pulmonary trunk. Nevertheless, a few millimeters of the septal summit, or the septal aspect of LVS, are present between the anterior part of the interventricular groove and the pulmonary trunk. The distance from the left coronary artery bifurcation to the first dominant septal perforator denotes the length of the septal margin of the LVS [8]. The annulus of the pulmonary valve and pulmonary trunk is present above the LVS septal margin. These structures are overlying the LVS in the most superior aspect. The right ventricular outflow tract correlates with the lower portion of the septal margin, and various amounts of epicardial adipose tissue are present between those structures (Figure 2C). From the septal margin of LVS, the first or sometimes second diagonal branch enters the LVS region while septal perforators penetrate the ventricular septum. Rarely, the right-sided branches occur, creating preconal ring anastomosis-arterial ring of Vieussens [21]. The anterior interventricular vein enters from the anterior aspect of the interventricular groove into the LVS.

In some cases, when the most dominant septal perforator is more proximal to the left coronary artery bifurcation, the anterior interventricular vein may not cross the septal margin of the LVS but is then located more distally, outside the LVS triangle. In an uncommon variation, the anterior interventricular vein may not be present within the LVS area as it may drain to the right, towards the anterior cardiac vein [22]. The presence of the myocardial bridges over the left anterior descending artery should also be mentioned, as their presence is not insignificant within the left coronary artery tree. Nevertheless, within the anterior interventricular artery, the myocardial bridges are usually located outside the LVS area as they are much more likely to be found in the middle segment of the artery $(75.3 \%)$, followed by distal (20.5\%) and proximal $(7.4 \%)$ segments of the left anterior interventricular artery [23,24].

Left Margin of LVS - mitral margin.

The left circumflex coronary artery, together with the accompanying left lateral cardiac nerve, forms the mitral (or inferior) boundary of the LVS. In the distal sector of the mitral margin, the small section of the great cardiac vein is also present (Figure 1) [25]. In some cases, the circumflex coronary artery is accompanied by the conus vein, which trespasses under the trunk of the left coronary artery (Figure 2A,B). The length of the mitral margin is equal to the length of the septal margin. This margin neighbors close to the mitral annulus (thus the name of the margin), left fibrous trigon, left atrium and the left atrial appendage base [19]. The left atrial appendage overlaps the mitral margin, most commonly covering around $80 \%$ of its length, but this may vary depending on the left atrial appendage body type (shape) [26].

In some cases, the mitral margin's superior aspect may be covered by the pulmonary trunk or left main pulmonary artery [15]. The first (or sometimes the second) obtuse marginal branch originates from the left circumflex coronary artery entering into the LVS from the mitral margin aspect. The great cardiac vein enters over a mitral margin of the LVS. It crosses the left circumflex coronary artery and then runs into the posterior aspect of the atrioventricular groove. Several spatial relationships between the great cardiac vein and the left circumflex coronary artery may be found, with the vein located over the artery being the most common [19]. The left phrenic nerve trespassing epicardially over the left atrial appendage and then directing to the left dome of the diaphragm may cross the mitral margin [27-30].

\section{Base of LVS - arcuate line}


The base of the LVS may be defined as a curved line, with the radius of this arc being the distance from the left coronary artery bifurcation to the first dominant septal perforator originating from the left anterior descending artery [8]. Thus, the base of the LVS creates an imaginary line over the left ventricle's epicardial surface that may be trespassed by ramus intermedius, diagonal branches and obtuse marginal branches of the left coronary artery (Figure 2B). Moreover, in some cases, the venous system (represented by the anterior interventricular vein or great cardiac vein with tributaries) may cross the arcuate line.

The biggest challenge in drawing the LVS base is depicting the proper septal perforator. Many septal perforators can be found in the left anterior descending artery (from one to three on the first $25 \mathrm{~mm}$ distance). The first anterior septal branch is usually the most prominent (40-60 $\mathrm{mm}$ in length) and provides the most important collateral channels. However, only $30 \%$ of normal angiograms demonstrate a large $(1.5 \mathrm{~mm}$ in diameter or larger) first septal perforator that distally arborizes into at least four branches. In $28 \%$ of cases, the first perforator is a small artery, with a further $24 \%$ of patients having two or three arteries comparable in size. Finally, in the last $18 \%$ of the hearts, the septal perforator diffuses into multiple small septal arteries [31] (Figure 3A,B). When only one septal perforator is present in the proximal aspect of the left anterior descending artery, the definition of the LVS is indisputable, whereas when there are more perforators, the LVS definition should take the perforator with the largest diameter (Figure 4A). There is another reason for choosing the most dominant perforator that relates to available imaging methods. In cardiac computed tomography angiography, the septal perforator imaging can usually visualize a vessel larger than $1 \mathrm{~mm}$ in diameter. Smaller vessels visible in the macroscopic dissection might be unnoticed in clinical assessment. 


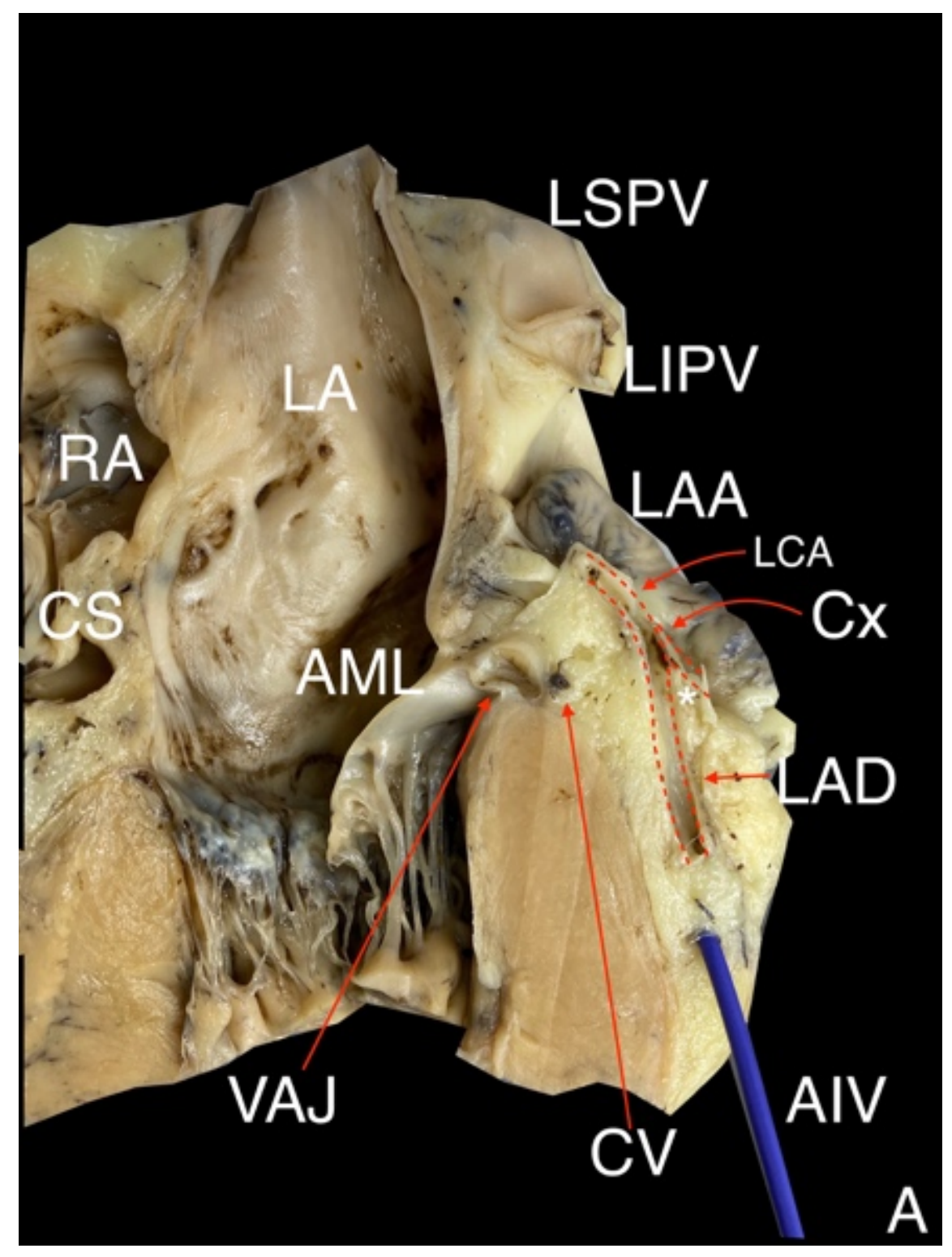




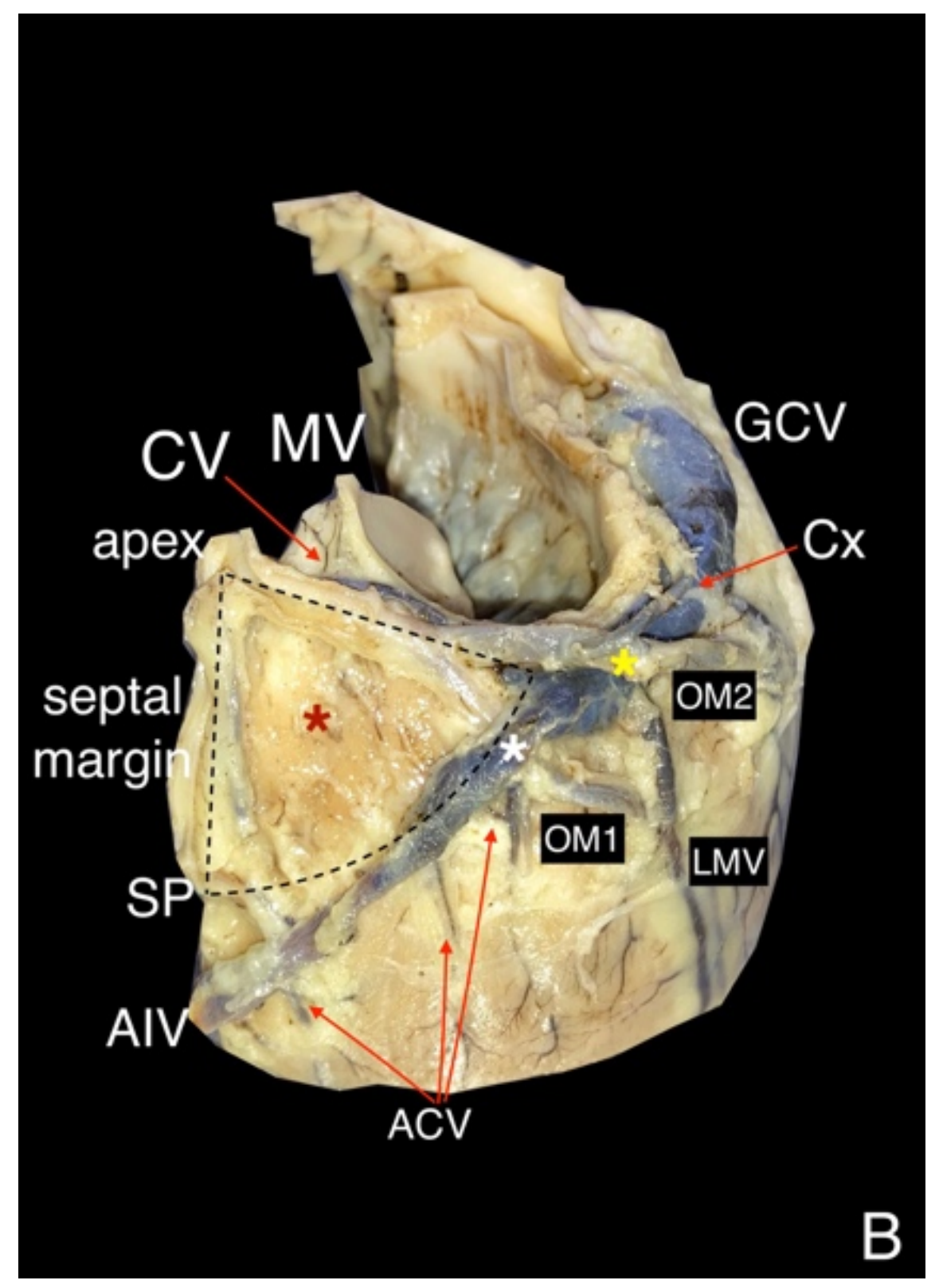




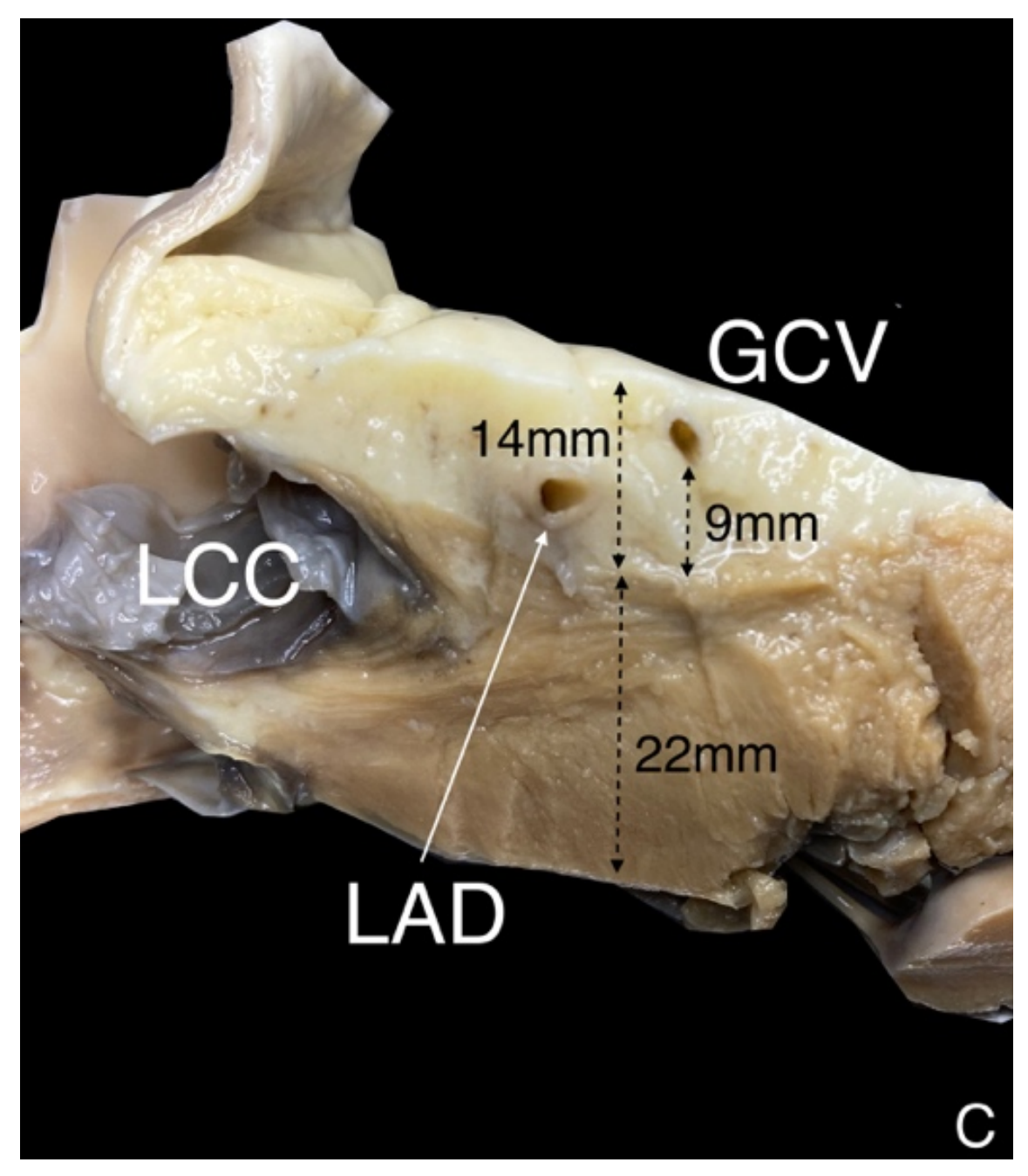

Figure 2. A - section in the septal margin with LVS aspect, close to VAJ the depression above is the left sinus of Valsalva and conus vein (CV) trespassing in front of it. B - LVS after EAT removal red Asterix, white Asterix GVC over OM1, yellow Asterix GCV below to the OM2, behind Cx conus vein marked; $\mathrm{C}$ dissection in L-R interleaflet trigon - thickness of LV and EAT was measured; Abbreviations:LVS = left ventricular summit; LAD = left anterior descending artery; LCA - left coronary artery; $\mathrm{Cx}=$ circumflex branch of left coronary artery; $\mathrm{GCV}=$ great cardiac vein; $\mathrm{AIV}=$ anterior interventricular vein; $\mathrm{SP}=$ septal perforator; OM = obtuse marginal; LAA = left atrial appendage; $\mathrm{MV}$ - mitral valve, VAJ - ventriculo aortic junction, CS - coronary sinus, RA - right atrium, LA - left atrium, AML - anterior mitral leaflet, LCC left coronary cusp, CV - conus vein, LSPV - left superior pulmonary vein, LIPV - left inferior pulmonary vein, ACV - anterior cardiac veins.

\section{Interior aspect}

Inside the LVS, the presence of the great cardiac vein is almost inevitable. However, LVS may come without a coronary sinus tributary when the short distance between bifurcation to septal perforator excludes vessels from the defined LVS area. In anatomical terminology, great cardiac vein begins at the heart's apex and ascends along the anterior longitudinal groove to the base of the heart, while in cardiology and radiology, the initial segment from the apex of the left ventricle to the LVS is named the anterior interventricular vein[7]. In definition, the anterior interventricular vein originates at the lower or middle third of the anterior 
interventricular groove, follows the groove adjacent to the left anterior descending artery, and angulates laterally toward the heart's base to form the great cardiac vein [2]. The coronary venous system lying in the LVS region is sunken in the epicardial adipose tissue, and distance to the left ventricular surface may be wary (Figure 2c). This distance might impact ventricular potential amplitude recorded from the great cardiac vein if the epicardial adipose tissue is significantly thick. Mostly, the venous system intersects coronary vessels deeply [Figure $4 \mathrm{~A}$ ], while in $\frac{1}{4}$ of the specimens, it does so superficially. The relationships between the great cardiac vein - anterior interventricular vein and the coronary arteries vary between patients [6]. The point of transition between the anterior interventricular vein and the great cardiac vein lies inside the LVS and arguably a significant source of epicardial idiopathic ventricular arrhythmias [9].The coronary venous system plays an essential role in the LVS division into the superior and inferior aspects. The superior aspect of the LVS is named an inaccessible area; nevertheless, it is recognizable also as the triangle of Brocq and Mouchet [18]. The difference in terminology is that the featured LVS base starts from the first dominant septal perforator while trigon of Brocq and Mouchet when the anterior interventricular vein crosses the anterior interventricular groove. Brocq and Mouchet trigon have five main variations dependent on vessel crossings and relations in heart groves [18]. The inaccessible area is almost triangular, closed at the bottom by the venous system. In some LVS, the superior aspect may dominate in size over the accessible area (figure 1A, B). The inaccessible area contents include the presence of proximal branches from coronary vessels, small veins, and a thick layer of epicardial adipose tissue covered by LAA and pulmonary trunk. Between the anterior interventricular vein / great cardiac vein line and arcuate line, the accessible part of the LVS is present. Mostly irregular in shape with the continuation of coronary vessels originated from the inaccessible area and anterior coronary veins draining into the coronary venous system. The density of coronary branches is significantly lower, as well as epicardial adipose tissue. Often uncovered by the LAA with epicardial approach possibility.

\section{LVS Size and Content}

The size of the LVS may vary and does not correlate with BMI, sex or age. The distance from left coronary artery bifurcation to the first septal perforator (length of the LVS septal margin) (Figure 3) and the angle of left coronary artery bifurcation determine the LVS size. The mean size of LVS measured in computed tomography is $263 \mathrm{~mm}^{2}$, with the mean inaccessible area being significantly bigger than the accessible area $\left(133\right.$ vs. $\left.95 \mathrm{~mm}^{2}\right)$. A Yamada equation calculation identifies the area with a high correlation to real LVS size $[8,15]$.

Inside the LVS area, the presence of the great cardiac vein is almost inevitable. However, LVS may come without a coronary venous tributary when there is a short distance from the left coronary artery bifurcation to the first dominant septal perforator that excludes venous vessels from the defined LVS region (Figure 2B and Figure 3A,B). In anatomical terminology, the great cardiac vein begins at the heart's apex. It ascends along the anterior interventricular groove to the base of the heart, while in cardiology and radiology, the initial segment of the great cardiac vein (from the apex of the left ventricle to the LVS area) is named the anterior intraventricular vein [22]. By definition, the anterior intraventricular vein originates at the lower or middle third of the anterior interventricular groove, follows the groove adjacent to the left anterior descending artery and angulates laterally toward the heart's base to form the great cardiac vein [7,32]. The point of transition between the anterior interventricular vein and the great cardiac vein lies inside the LVS, and arguably, it is a significant source of epicardial idiopathic ventricular arrhythmias [33].

The relationships between the great cardiac vein and the coronary arteries within the LVS region vary between individuals $[19,34,35]$. There are four main aspects of the GCV course relative to the left coronary branches: (1) side of initial course relative to the left anterior interventricular artery, (2) superficial or deep crossing of the left anterior interventricular artery from a right side initial course, (3) proximal or distal crossing of the circumflex branch of the left coronary artery and (4) superficial or deep crossing of the circumflex branch of the left coronary artery. From these aspects, Bales et al. present 12 theoretical relationship combinations [36]. Studies report that the great cardiac vein is found either on the right or left side of its related artery in the interventricular groove, more often crossing the left anterior interventricular artery superficially. The 
relationships of the great cardiac vein to the circumflex artery are predominantly proximal (close relative to the apex of the LVS). Approximately $60 \%$ of the great cardiac veins crossed superficially to the circumflex artery in most studies [22,37]. It is interesting to note that when the great cardiac vein crossed the left anterior interventricular artery superficially, it more often crossed the circumflex artery superficially and that when the great cardiac vein crossed the left anterior interventricular deeply, it more often crossed the circumflex artery deeply. Figure 2B presents the rarest possible variation with deep crossing to left anterior interventricular and circumflex artery in the distal relation.

The coronary vessel system lying in the LVS region is sunken in the relatively abundant epicardial adipose tissue. The distance from the epicardium to the surface of the left ventricular myocardium is thus significant (up to $10 \mathrm{~mm}$ ). The thickness of the adipose tissue may vary significantly between individuals and between different regions of the LVS (Figure 2) [38,39]. For example, the amount of epicardial adipose tissue along the arcuate line is significantly smaller than in apical aspects of the LVS (Figure 2). This distance might impact ventricular potential amplitude recorded from the great cardiac vein if the epicardial adipose tissue is sufficiently thick. Moreover, the thick adipose tissue layer may have a pro-arrhythmogenic activity and negatively influence the success rate of electrophysiological procedures performed within the LVS [40-42]. 


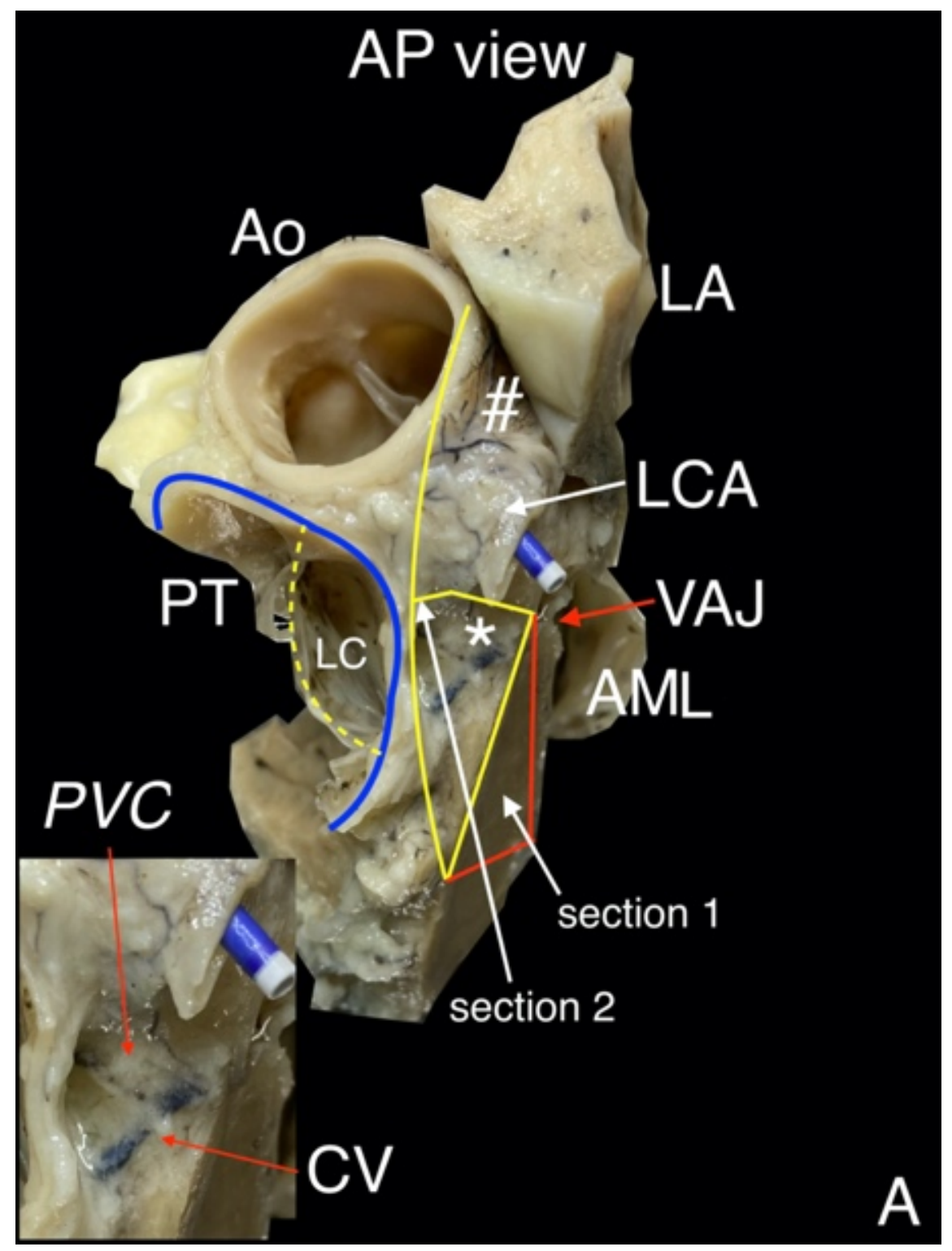




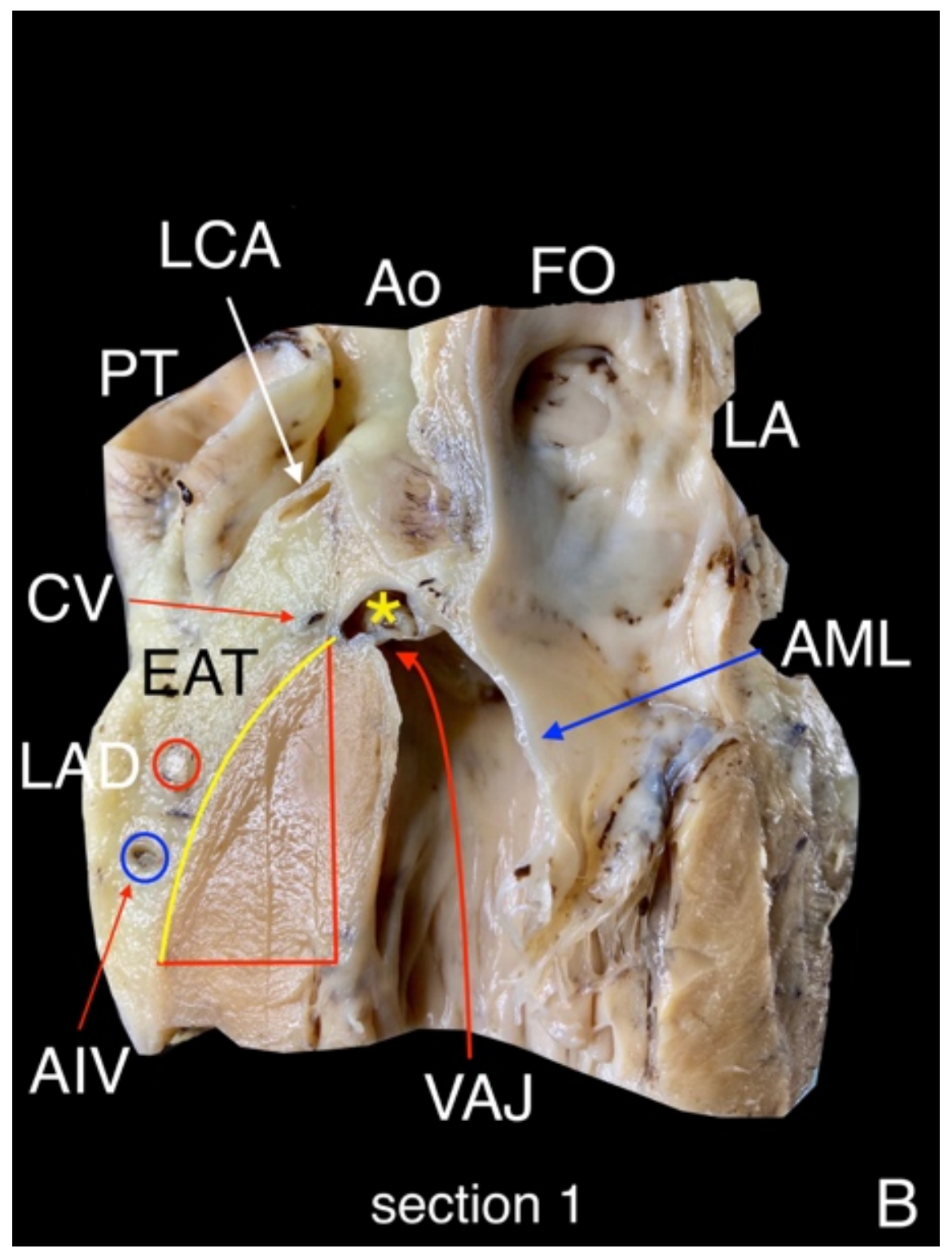




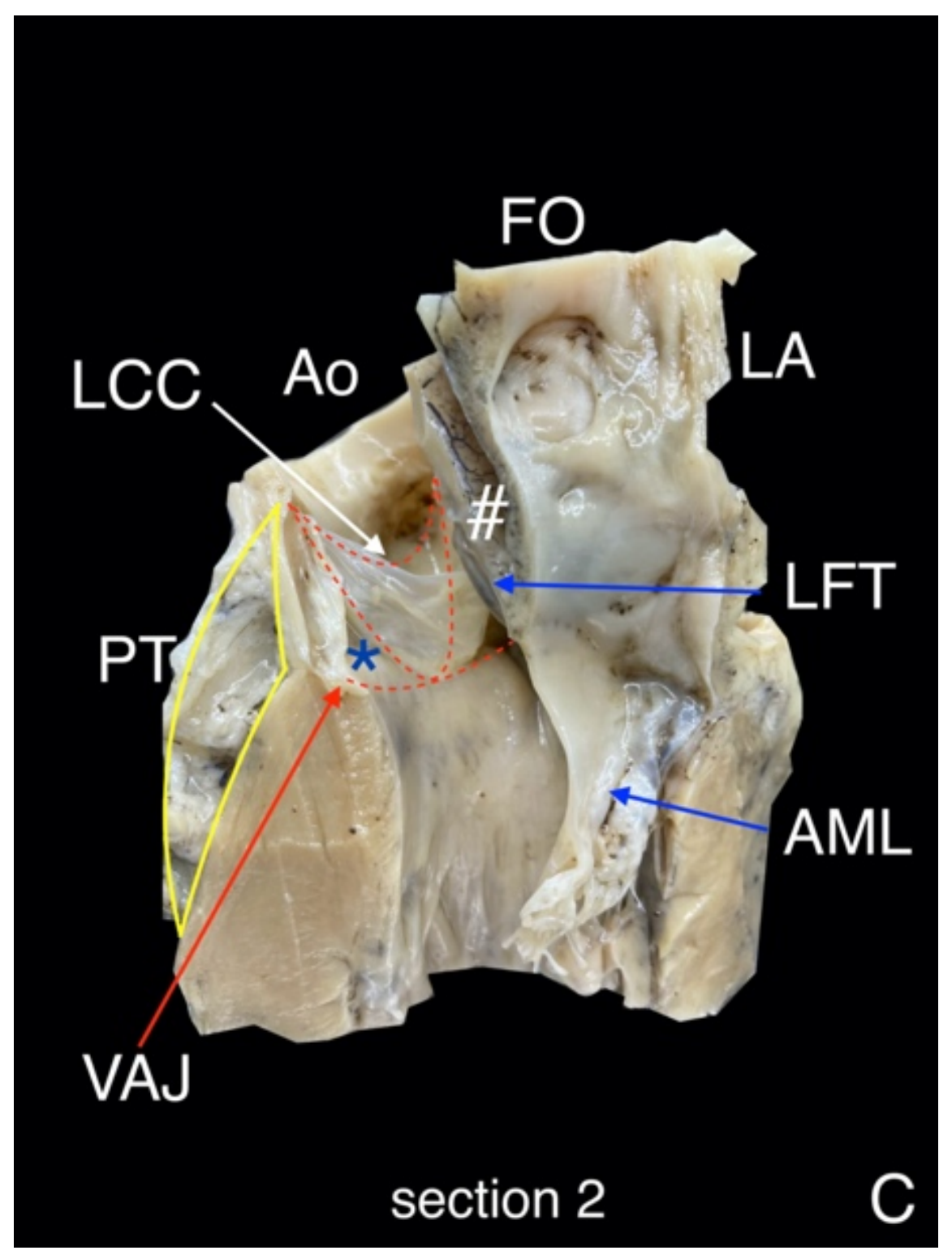

Figure $3 \mathrm{~A}$ - block of heart with septal margin of the heart, B - section 1; cut in the anterior interventricular groove, $\mathrm{C}$ - section 2; cut on the lateral aspect of the septal summit with the opening of the left coronary cusp; Abbreviations: Ao - Aorta, PT - pulmonary trunk, LC left cusp of the pulmonic valve, AML anterior mitral leaflet, VAJ - ventriculo - aortic junction, LCA - left coronary artery, LA - left atrium, FO - foramen ovale, AIV - anterior interventricular vein, LAD - left anterior descending, LCC - left coronary cusp (red lines presents virtual LCC), LFT - left fibrous trigon, EAT - epicardial adipose tissue, CV - conus vein, $P V C$ - the posterior vein of conus; white Asterix, septal summit, yellow asterisk, left sinus of Valsalva, blue asterisk - left-right interleaflet trigon, hashtag - sinus transversus pericardii.

\section{LVS nourishment and innervation.}

The myocardium in the LVS area receives the arterial blood from perforating arteries branching off from the proximal segments of left coronary artery branches. The venous collection drains into the coronary sinus (via anterior coronary veins into the anterior interventricular vein or great cardiac vein) from the lower 
aspect of LVS and via noncoronary sinus tributaries from the apical aspect and septal side of LVS [43-45]. The left or right superior septal veins drain the superior third of the interventricular septum (ventricular outflow tracts). The left superior septal vein, the longest and largest intramural venous channel, can reach 2-3 $\mathrm{mm}$ in diameter [22] and can be used in interventional procedures [46-49]. The venous drainage from the septal summit is most commonly into the right atrium via the intramural sinus [50], also known as veins of Vieussens or communicating vein [51]. This also involves veins that drain the adipose tissue that cover the conus arteriosus [43]. An important fact is that this region is abundant in venous anastomoses with the axillary orientated circle embracing the entire heart, consisting of the coronary sinus-great cardiac vein-small cardiac vein-conus vein, and further intercommunicating veins [22].

The epicardial region of LVS is covered by the fibers of the intrinsic cardiac nervous autonomic system [52$54]$, gathering nearly $6 \%$ of all ganglionated plexuses of the heart $[20,55]$. These plexuses are embedded in the epicardial adipose tissue. The first portion of the left coronary ganglionated subplexus with preganglionated nerves is densely distributed nearby the pulmonary trunk and ascending aorta in septal summit region. Postganglionated nerves extend into anterior, lateral and (in part) posterior walls of the left ventricle. Moreover, thin short postganglionated nerves proceed on the interior surface of the left atrial appendage along the atrial branches of the circumflex branch of the left coronary artery [20]. The subendocardially located Purkinje network that originates from the left bundle branch's anterior division most likely activates the LVS region. The anterior division of the left bundle branch proceeds toward the base of the superolateral papillary muscle of the mitral valve. It is formed of many fine strands coursing anteriorly to the free wall [56-58]; thus, this segment is most likely to support the LVS region. However, both networks from anterior and posterior divisions of the left bundle branch are widely interconnected [59,60]. Another argument for anterior division distribution in the LVS region is the possibility of mapping and ablating the left anterior fascicle from the right aortic sinus [61].

\section{LVS Accessibility and Ablations}

Over $12 \%$ of ventricular arrhythmias from the left ventricle have a source over the epicardial surface of the left ventricle [8]. The most common electrocardiographic template for LVS arrhythmias is V2 lead pattern break qrs [62]. The ablation of ventricular arrhythmias from the LVS is challenging and requires various approaches. Another pattern of outflow tract ventricular arrhythmia is with abrupt R-wave transition in the V3 lead with its source in the septal margin of the LVS [17].

Access to the LVS is required when the ventricular arrhythmia source is localized in this particular area. The coronary venous system plays an essential role in the LVS division into the superior and inferior aspects. The superior aspect of the LVS, because of the dense vasculature in which damage may be life-threatening, is defined as an inaccessible area. It is also recognizable as the triangle of Brocq and Mouchet [63-67]. The difference may be found in both the terminology and boundaries of both triangles, where the first dominant septal perforator marks the LVS base.

In contrast, the trigon of Brocq and Mouchet base is marked by the point where the anterior interventricular vein crosses the anterior interventricular groove. The Brocq and Mouchet trigon has five main variations dependent on vessel crossings and their relations in heart groves, while the LVS area is independent of such variants [63,64]. The inaccessible area is almost triangular, closed at the bottom by the venous system. Usually, the superior aspect dominates in size over the accessible area, and frequently, the LVS may be constituted only by inaccessible area (Figures 1, 2B, and 3A). The inaccessible area contents include proximal branches from coronary vessels, small veins and a thick layer of epicardial adipose tissue covered by the left atrial appendage and pulmonary trunk.

The anterior interventricular artery/great cardiac vein line and LVS arcuate line, the accessible part of the LVS, are present. The accessible area is mostly irregular in shape, with the presence of coronary vessels originating from the inaccessible area and anterior coronary veins draining into the coronary venous system. In addition, the density of coronary branches is significantly lower, and epicardial adipose tissue is less abundant than in inaccessible areas. Thus, it is named "accessible". Moreover, the accessible LVS area is 
often uncovered by the left atrial appendage with epicardial approach possibility [68].

Because the LVS is an epicardial region, the approach to the LVS may be indirect or direct. The indirect method uses the adjacent structures to achieve closeness to the earliest activation point exiting the arrhythmia source. Because of a lack of such reasonable access points, these were defined as the vertices of the "Bermuda triangle" [69-71]. However, delivery of the proper radiofrequency energy to the arrhythmia source, avoiding at the same time the coronary artery damage, may be a challenge $[70,72,73]$. Therefore, coronary angiography or cardiac computed tomography imaging is strongly recommended before any procedure within the LVS region [74-81].

The nearest relation to the LVS apex or septal aspect of the LVS is the left coronary cusp of the aortic valve or right-left interleaflet triangle $[7,17,82]$ (Figure 4). The septal margin approach is possible to perform from the left coronary cusp of the pulmonary valve and pulmonary trunk in the superior aspect and from the right ventricular outflow tract in the inferior aspect of allied anatomical conditions [SP2] (Figure 4). The septal perforators may also reach the LVS myocardium near the septal margin. The mitral margin may be accessible from the left atrial appendage or great cardiac vein (Figure 3) [33]. A mid aspect of the LVS can be attainable from the venous system: the great cardiac vein, the anterior interventricular vein, the communicating vein, the conus vein and septal venous perforators, or recently proposed left atrial appendage, which covers nearly $75 \%$ of the LVS region [15,33,51] (Figures 3 and 4).

Nevertheless, access from the coronary venous vasculature may be challenging because of the complex anatomy of the cardiac venous system. Although the distance between the coronary veins and left ventricular myocardium may be significant (up to $20 \mathrm{~mm}$ ), the range of the ThermoCool electrodes allows reaching the arrhythmia source from the epicardial aspect, making ablation successful. In addition, recent long-term observations from ventricular ablations in the LVS region using a bipolar technique show reduction in unattainable arrhythmias [83].

Access from the endocardial region toward the epicardial aspect of the LVS is almost impossible because of the thickness of the left ventricular myocardium. Only the subvalvular aspect of the left ventricle endocardium is thin enough to process the energy to the LVS (Figure 4) [17,84].

The direct approach to the LVS provides access through the pericardial sac. This access also has a limitation because of thick epicardial adipose tissue and the coronary vessel density. The only reachable part of LVS via direct epicardial aspect is an accessible area. The superior portion of LVS is dangerous for pericardial penetration. It increases the risk of major and minor complications, such as intrapericardial bleeding, coronary artery stenosis, delayed tamponade and incidental right ventricle puncture [85-89]. Table 1 summarizes possible approaches to the LVS area. 


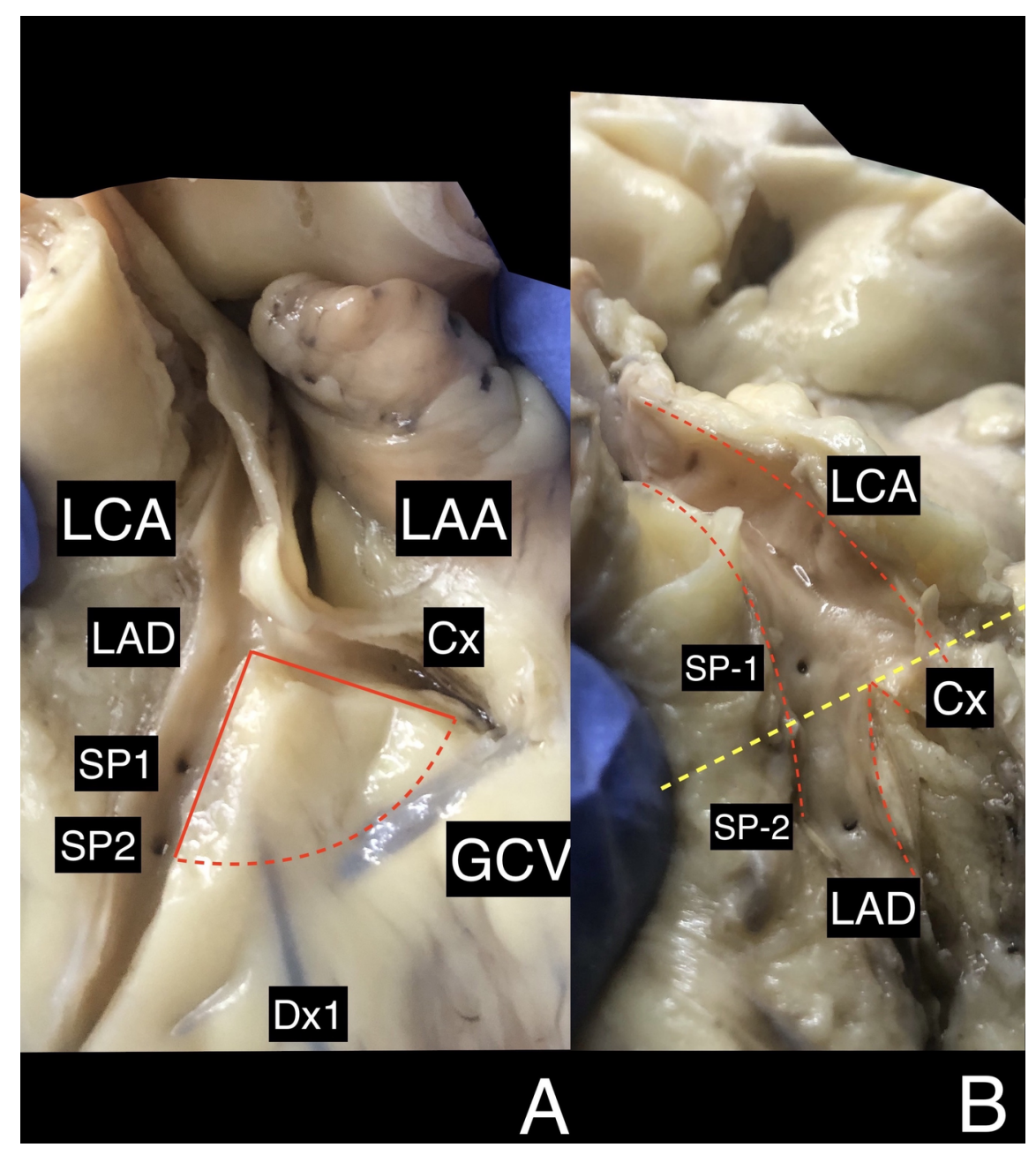




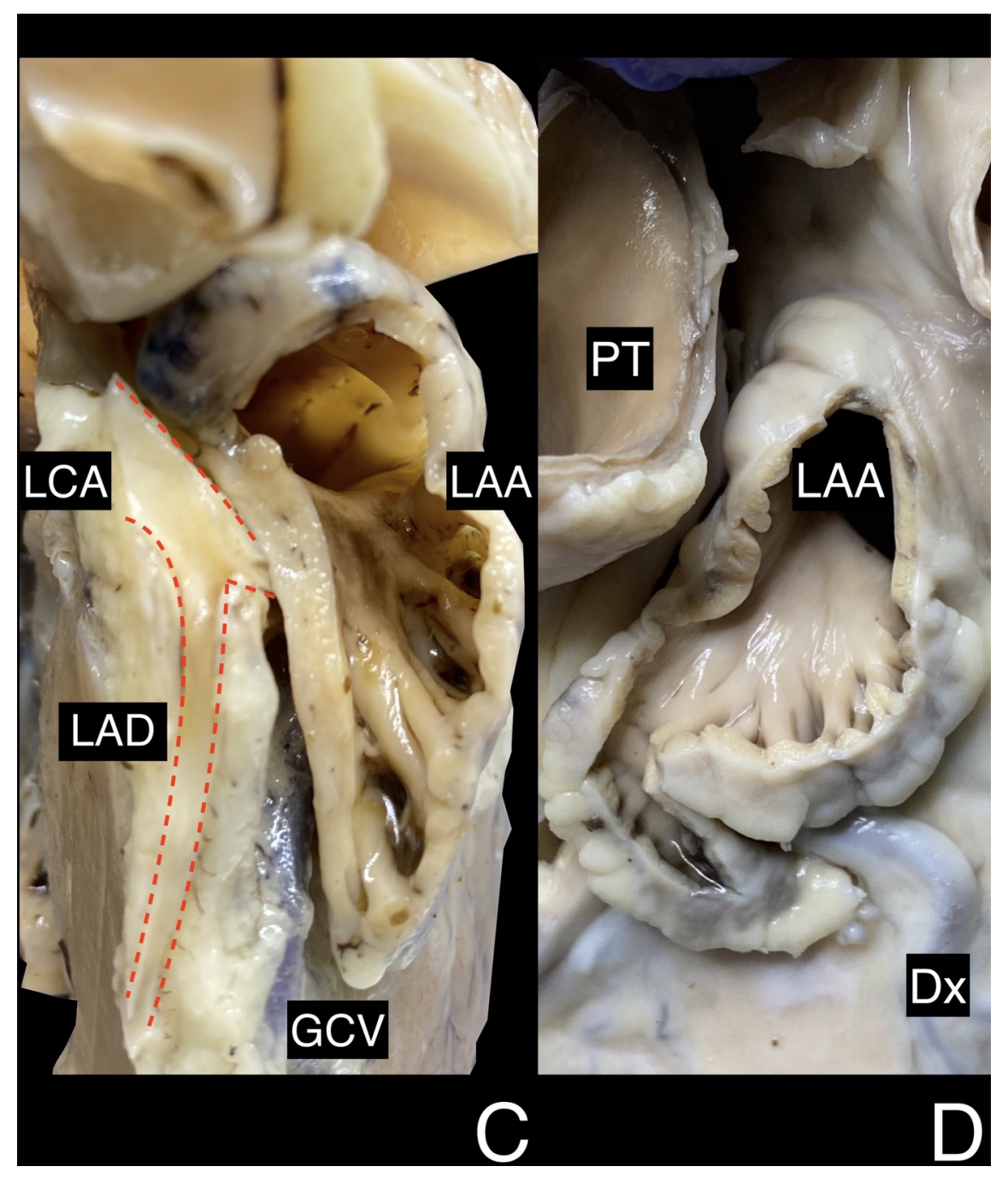




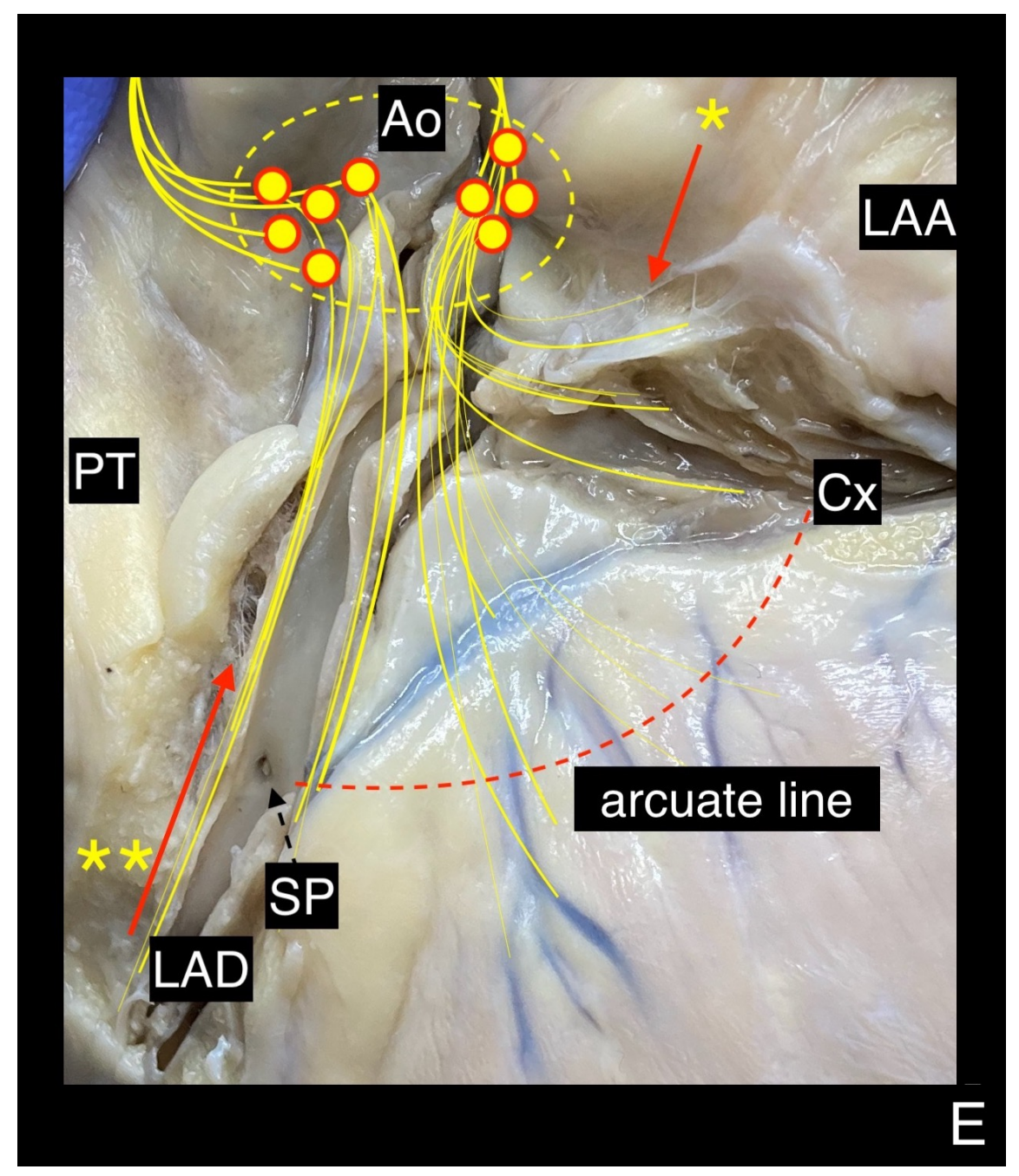

Figure 4 (A) Septal perforators (SP) in LAD, SP1 - smaller and SP2 - bigger; the area of LVS has only an inaccessible area; (B) - SP in proximal distance, SP - 1 in the LCA trunk, SP - 2 - dominant define very small LVS area; (C) - the presence of open LAA over LVS via the thickness of LAA and EAT; (D) the floor of LAA over LVS; (E) schematic distribution of left coronary subganglion with postganglionic autonomic fibers, yellow asterix- nerve fiber conecting with surface of the left auricle along the atrial branches of the circumflex left coronary artery; double yellow asterix - fibers from left coronary cardiac nerve. Abbreviations: LCA - left coronary artery, LAD - left anterior descending, SP - septal perforator, $\mathrm{Cx}$ - circumflex branch, GCV - great cardiac vein, Dx - diagonal branch, EAT - epicardial adipose tissue,

Table 1. List of approaches to the LVS and possible ablation coverage in the individual regions.

\section{Approach to LVS}

Right ventricular outflow track

Pulmonary trunk/left pulmonary artery

Aorta-left sinus of Valsalva/left coronary cusp

Aorta-L-R inter leaflet trigon

Left atrial appendage

\section{Reachable LVS Region}

Septal margin, right aspect of LVS accessible area, lower right septal sun Septal margin, right aspect of LVS inaccessible area, higher right septal Septal summit, apex of LVS, aortic-mitral continuity

Septal summit, apex of LVS

Mitral margin of LVS, accessible and inaccessible area (depends on the $n$ 
Great cardiac vein/anterior interventricular vein

Mitral margin of LVS, between accessible and inaccessible areas (depend Epicardial-subxiphoid access Accessible area of LVS from septal to mitral margin

The overview of publications focusing on ablations of ventricular arrhythmias arising from the LVS region with reported success and complication rates of procedures is presented in Table 2.

Table 2. Reported success and complication rates of LVS ventricular arrhythmia ablation procedures.

\begin{tabular}{|c|c|c|c|c|}
\hline Study & LVS Access (if Specified) & Total Number of Cases & Number of Successful Cases & $\mathrm{Nu}$ \\
\hline Obel, 2006 [33] & TotalGCV & 5 & 5 & 0 \\
\hline Daniels, 2006 [72] & Total & 11 & 11 & 0 \\
\hline GCV & 9 & & & \\
\hline Epi & 2 & & & \\
\hline Yamada, 2008 [75] & Total & 44 & 44 & 1 \\
\hline $\mathrm{LCC}$ & 24 & & & \\
\hline $\mathrm{RCC}$ & 14 & & & \\
\hline $\mathrm{NCC}$ & 1 & & & \\
\hline R-L ILT & 5 & & & \\
\hline Kumagai, 2008 [73] & Total & 45 & 40 & 0 \\
\hline $\mathrm{AMC}$ & 3 & & & \\
\hline MA & 8 & & & \\
\hline $\mathrm{LCC} / \mathrm{RCC}$ & 32 & & & \\
\hline Epi & 2 & & & \\
\hline Sacher, 2010 [85] & TotalEpi & 136 & 64 & 8 \\
\hline Yamada, 2010 [8] & Total & 27 & 22 & 0 \\
\hline GCV & 14 & & & \\
\hline Epi & 4 & & & \\
\hline Frankel, 2014 [12] & RVOT & 2 & 2 & 0 \\
\hline Santangeli, 2015 [38] & TotalEpi & 23 & 5 & no \\
\hline Yamada, $2015[86]$ & Total & 64 & 58(only inaccesabile area failure) & 0 \\
\hline GCV & 36 & & & \\
\hline $\mathrm{AMC}$ & 28 & & & \\
\hline Marai, 2016 [71] & Total & 10 & 10 & 0 \\
\hline R-L ILT & 5 & & & \\
\hline AIV-GCV & 1 & & & \\
\hline NCC & 1 & & & \\
\hline $\mathrm{LCC}$ & 2 & & & \\
\hline $\mathrm{RCC}$ & 1 & & & \\
\hline Hayashi, 2017 [70] & Total & 12 & 7 & 0 \\
\hline RVOT & 7 & & & \\
\hline LCC & 1 & & & \\
\hline AIV & 2 & & & \\
\hline Epi & 2 & & & \\
\hline Yamada, 2017 [87] & not specified & 229 & 212 & no \\
\hline Komatsu, 2018 [51] & Total & 31 & & \\
\hline GVC & 14 & 10 & 1 & \\
\hline other & 17 & 17 & 0 & \\
\hline Benhayon, 2018 [68] & LAA & 1 & 1 & 0 \\
\hline Yakubov, 2018 [70] & LAA & 1 & 1 & 0 \\
\hline Candemir, 2019 [88] & not specified & 21 & 15 & 0 \\
\hline
\end{tabular}


Liao, 2020 [17]

Igarashi, 2020 [83]

Chung, 2020 [89]

GCV

EPI

RL ILT

\section{R-L ILT}

not specified

Total

91

6

139
20

18

238
16

16

199

RL ILT $=$ right-left interleaflet region, GCV $=$ great cardiac vein, Epi $=$ epicardial approach, $\mathrm{RVOT}=$ right ventricular outflow track, AMC = aortic-mitral continuity, $\mathrm{LCC}=$ left coronary cusp, $\mathrm{NCC}=$ noncoronary cusp, $\mathrm{RCC}=$ right coronary cusp, AIV $=$ anterior interventricular vein, $\mathrm{MA}=$ mitral annulus.

10. Septal Summit/Septal Aspect of the LVS

Next to the LVS concept, the second idea of the so-called "septal summit" was proposed. The septal summit is the most superior part of the interventricular septum, located near the LVS septal margin, more toward the pulmonary trunk. The septal summit extends from the ventriculo-aortic junction down to the first dominant septal perforator (Figure 1). The structures neighboring the septal summit are the right-left interleaflet trigon from the top, the left pulmonary sinus from the right aspect and the anterior interventricular groove's content from the lateral side. Above the apex of the LVS (under the left coronary artery), the septal summit corresponds with aortic-mitral continuity.

In contrast to the LVS, the septal summit cannot be reached from the left coronary aortic cusp, the left ventricular endocardial aspect or the left atrial appendage. It is worth emphasizing that the septal summit is central to the parasternal long-axis view in transthoracic heart ultrasound examination [90]. The abovementioned right-left interleaflet trigon is adjacent to the mid-posterior septal aspect of the right ventricular outflow tract [91]. Within the septal summit, the conus vein and posterior veins of the cone, also known as communicating veins, can be present (Figure 4A) [51].

\section{Conclusions}

Providing systematic and comprehensive anatomical descriptions and proper terminology in the LVS region may facilitate the exchanging of information among anatomists and electrophysiologists, increasing knowledge of this cardiac region. We postulate that the most dominant septal perforator (not the first septal perforator) should characterize the LVS definition. Abundant epicardial adipose tissue overlying the LVS myocardium may affect arrhythmogenic processes and electrophysiological procedures within the LVS region. The LVS is divided into two clinically significant regions: accessible and inaccessible areas. Rich arterial and venous coronary vasculature and a relatively dense network of cardiac autonomic nerve fibers are present within the LVS boundaries. Although the approach to the LVS may be challenging, it may be executed indirectly using the surrounding structures. Further research on LVS morphology and physiology should increase the safety and effectiveness of invasive electrophysiological procedures performed within this region of the human heart.

\section{References}

1. Roberts, W.; Salandy, S.; Mandal, G.; Holda, M.K.; Tomaszewski, K.A.; Gielecki, J.; Tubbs, R.S.; Loukas, M. Across the centuries: Piecing together the anatomy of the heart. Transl. Res. Anat. 2019, 17, 100051, doi:10.1016/j.tria.2019.100051.

2. Dudkiewicz, D.; Słodowska, K.; Jasińska, K.A.; Dobrzynski, H.; Hołda, M.K. The clinical anatomy of the left atrial structures used as landmarks in ablation of arrhythmogenic substrates and cardiac invasive procedures. Transl. Res. Anat. 2021, 23, 100102, doi:10.1016/j.tria.2020.100102.

3. Whiteman, S.; Alimi, Y.; Carrasco, M.; Gielecki, J.; Zurada, A.; Loukas, M. Anatomy of the cardiac chambers: A review of the left ventricle. Transl. Res. Anat. 2021, 23, 100095, doi:10.1016/j.tria.2020.100095.

4. Kucybała, I.; Ciuk, K.; Klimek-Piotrowska, W. Clinical anatomy of the human heart atria and internal septum-Anatomical basis for interventional cardiologists and elektrocardiologists. Part 1: Right atrium and 
interatrial septum. Kardiol. Pol. 2018, 76, 499-509.

5. Ciuk, S.; Janas, P.; Klimek-Piotrowska, W.; Clinical anatomy of the human heart atria and internal septum - anatomical basis for interventional cardiologists and elektrocardiologists. Part 2: Left atrium. Kardiol. Pol. 2018, 76, 510-519.

6. Kumagai, K. Idiopathic ventricular arrhythmias arising from the left ventricular outflow tract: Tips and tricks. J. Arrhythmia 2014, 30, 211-221, doi:10.1016/j.joa.2014.03.002.

7. Enriquez, A.; Malavassi, F.; Saenz, L.C.; Supple, G.; Santangeli, P.; Marchlinski, F.E.; Garcia, F.C. How to map and ablate left ventricular summit arrhythmias. Heart Rhythm. 2017, 14, 141-148, doi:10.1016/j.hrthm.2016.09.018.[M1]

8. Yamada, T.; McElderry, H.T.; Doppalapudi, H.; Okada, T.; Murakami, Y.; Yoshida, Y.; Yoshida, N.; Inden, Y.; Murohara, T.; Plumb, V.J.; et al. Idiopathic ventricular arrhythmias originating from the left ventricular summit: Anatomic concepts relevant to ablation. Circ. Arrhythmia Electrophysiol. 2010, 3, 616-623, doi:10.1161/CIRCEP.110.939744.

9. McAlpine, W.A. Heart and Coronary Arteries: An Anatomical Atlas for Clinical Diagnosis, Radiological Investigation, and Surgical Treatment; Springer: New York, NY, USA, 1975; pp. 160-178.

10. Loukas, M.; Bilinsky, S.; Bilinsky, E.; el-Sedfy, A.; Anderson, R.H. Cardiac veins: a review of the literature. Clin Anat. 2009, Jan;22(1):129-45. doi: 10.1002/ca.20745. PMID: 19097063.

11. Mazur, M.; Żabówka, A.; Bolechała, F.; Kopacz, P.; Klimek-Piotrowska, W.; Hołda, M.K. Variations and angulation of the coronary sinus tributaries: Implications for left ventricular pacing. Pacing Clin. Electrophysiol. 2019, 42, 423-430.

12. Frankel, D.S.; Mountantonakis, S.E.; Dahu, M.I.; Marchlinski, F.E. Elimination of ventricular arrhythmias originating from the anterior interventricular vein with ablation in the right ventricular outflow tract. Circ. Arrhythmia Electrophysiol. 2014, 7, 984-985, doi:10.1161/CIRCEP.114.001456.

13. Mazur, M.; Holda, M.; Koziej, M.; Klimek-Piotrowska, W.; Kuniewicz, M.; Matuszyk, A.; Konarska, M.; Jaworek, J.; Mróz, I. Morphology of tributaries of coronary sinus in humans. Folia Med. Crac. 2015, 55, $5-13$.

14. Kassem, M.W.; Lake, S.; Roberts, W.; Salandy, S.; Loukas, M. Cardiac veins, an anatomical review. Transl. Res. Anat. 2021, 23, 100096., doi:10.1016/j. tria.2020.100096.

15. Kuniewicz, M.; Krupiński, M.; Gosnell, M.; Budnicka, K.; Jakob, N.; Karkowski, G.; UrbańczykZawadzka, M.; Lelakowski, J.; Walocha, J. Applicability of computed tomography preoperative assessment of the LAA in LV summit ablations. J. Interv. Card. Electrophysiol. 2020, 14, doi:10.1007/s10840-02000817-8.

16. Michałowska, I.M.; Hryniewiecki, T.; Kwiatek, P.; Stokłosa, P.; Swoboda-Rydz, U.; Szymański, P. Coronary Artery Variants and Anomalies in Patients With Bicuspid Aortic Valve. J. Thorac. Imaging 2016, 31, 156-162, doi:10.1097/RTI.0000000000000205.

17. Liao, H.; Wei, W.; Tanager, K.S.; Miele, F.; Upadhyay, G.A.; Beaser, A.D.; Aziz, Z.; Nayak, H.M.; Ozcan, C.; Nishimura, T.; et al. Left ventricular summit arrhythmias with an abrupt $\mathrm{V}_{3}$ transition: Anatomy of the aortic interleaflet triangle vantage point. Heart Rhythm. 2021, 18, 10-19, doi:10.1016/j.hrthm.2020.07.021.

18. Li, A.; Zuberi, Z.; Bradfield, J.S.; Zarif, J.K.; Ward, D.E.; Anderson, R.H.; Shivkumar, K.; Saba, M.M. Endocardial ablation of ventricular ectopic beats arising from the basal inferoseptal process of the left ventricle. Heart Rhythm. 2018, 15, 1356-1362, doi:10.1016/j.hrthm.2018.04.029.

19. Ishizawa, A.; Fumon, M.; Zhou, M.; Suzuki, R.; Abe, H. Intersection patterns of human coronary veins and arteries. Anat. Sci. Int. 2008, 83, 26-30, doi:10.1111/j.1447-073X.2007.00200.x. 
20. Pauza, D.H.; Skripka, V.; Pauziene, N.; Stropus, R. Morphology, distribution, and variability of the epicardiac neural ganglionated subplexuses in the human heart. Anat. Rec. 2000, 259, 353-382, doi:10.1002/1097-0185(20000801)259:4.

21. Loukas, M.; Patel, S.; Cesmebasi, A.; Muresian, H.; Tubbs, R.S.; Spicer, D.; Dabrowski, M. The clinical anatomy of the conal artery. Clin. Anat. 2016, 29, 371-379, doi:10.1002/ca.22469.

22. von Lüdinghausen, M.; The venous drainage of the human myocardium. Adv. Anat. Embryol. Cell Biol. 2003, 168, 1-104, doi:10.1007/978-3-642-55623-4.

23. Roberts, W.; Charles, S.M.; Ang, C.; Holda, M.K.; Walocha, J.; Lachman, N.; Tubbs, R.S.; Loukas, M. Myocardial bridges: A meta-analysis. Clin. Anat. 2021, 34, 685-709, doi:10.1002/ca.23697.

24. Kosiński, A.; Grzybiak, M.; Skwarek, M.; Hreczecha, J. Distribution of muscular bridges in the adult human heart. Folia Morphol. 2004, 63, 491-498.

25. Janes, R.D.; Brandys, J.C.; Hopkins, D.A.; Johnstone, D.E.; Murphy, D.A.; Armour, J.A. Anatomy of human extrinsic cardiac nerves and ganglia. Am. J. Cardiol. 1986, 57, 299-309, doi:10.1016/00029149(86)90908-2.

26. Slodowska, K.; Szczepanek, E.; Dudkiewicz, D.; Holda, J.; Bolechała, F.; Strona, M.; Lis, M.; Batko, J.; Koziej, M.; Holda, M.K. Morphology of the lest atrial appendage-introduction of a new simplified shape-based classification system. Heart Lung Circ. 2021, 30, 1014-1022.

27. Whiteman, S.; Saker, E.; Courant, E.; Salandy, S.; Gielecki, J.; Zurada, A.; Loukas, M. An anatomical review of the left atrium. Transl. Res. Anat. 2019, 17, 100052, ISSN 2214-854X, doi:10.1016/j.tria.2019.100052.

28. Huemer, M.; Wutzler, A.; Parwani, A.S.; Attanasio, P.; Haverkamp, W.; Boldt, L.H. Mapping of the left-sided phrenic nerve course in patients undergoing left atrial catheter ablations. Pacing Clin. Electrophysiol. 2014, 37, 1141-1148, doi:10.1111/pace.12422.

29. Kowalski, M.; Ellenbogen, K.A.; Koneru, J.N. Prevention of phrenic nerve injury during interventional electrophysiologic procedures. Heart Rhythm. 2014, 11, 1839-1844, doi:10.1016/j.hrthm.2014.06.019.

30. Fukumoto, K.; Takatsuki, S.; Jinzaki, M.; Yamada, M.; Tanimoto. K.; Nishiyama, N.; Aizawa, Y.; Hagiwara, Y.; Fukuda, Y.; Kimura, T.; Miyoshi, S.; et al. Three-dimensional imaging and mapping of the right and left phrenic nerves: Relevance to interventional cardiovascular therapy. Europace 2013, 15, 937-943, doi:10.1093/europace/eus439.

31. Stoney, W.S.; Vernon, R.P.; Alford, W.C.; Burrus, G.R.; Thomas, C.S. Revascularization of the septal artery. Ann. Thorac. Surg. 1976, 21,2-6.

32. Spencer, J.; Anderson, S.; Iaizzo, P. Human Coronary Venous Anatomy for Interventions. J. Card. Trans. Res. 2013, 6, 208-217.

33. Obel, O.A.; d'Avila, A.; Neuzil, P.; Saad, E.B.; Ruskin, J.N.; Reddy, V.Y. Ablation of left ventricular epicardial outflow tract tachycardia from the distal great cardiac vein. J. Am. Coll. Cardiol. 2006, 48, 1813-1817, doi:10.1016/j.jacc.2006.06.006.

34. Holda, M.K.; Koziej, M.; Holda, J.; Tyrak, K.; Piatek, K.; Krawczyk-Ozóg, A.; KlimekPiotrowska. W. Spatial relationship of blood vessels within the mitral isthmus line. Europace 2018, 20, 706-711, doi:10.1093/europace/euw423.

35. Holda, M.K.; Holda, J.; Strona, M.; Koziej, M.; Klimek-Piotrowska, W. Blood vessels and myocardial thickness within the left atrial appendage isthmus line.Clin. Anat. 2018, 31, 1024-1030.

36. Bales, G.S. Great cardiac vein variations. Clin. Anat. 2004, 17, 436-443, doi:10.1002/ca.10248. 
37. Pejkovic, B.; Bogdanovic, D. The great cardiac vein. Surg. Radiol. Anat. 1992, 14, 23-28, doi:10.1007/BF01628039.

38. Villasante Fricke, A.C.; Lacobellis, G.; Epicardial Adipose Tissue: Clinical Biomarker of CardioMetabolic Risk. Int. J. Mol. Sci. 2019, 20, 5989, doi:10.3390/ijms20235989.

39. Rabkin, S.W. The relationship between epicardial fat and indices of obesity and the metabolic syndrome: A systematic review and meta-analysis. Metab. Syndr. Relat. Disord. 2014, 12, 31-42, doi:10.1089/met.2013.0107.

40. Couselo-Seijas, M.; Rodríguez-Mañero, M.; González-Juanatey, J.R.; Eiras, S. Updates on epicardial adipose tissue mechanisms on atrial fibrillation. Obes. Rev. 2021, 17, e13277, doi:10.1111/obr.13277.

41. Samanta, R.; Pouliopoulos, J.; Thiagalingam, A.; Kovoor, P. Role of adipose tissue in the pathogenesis of cardiac arrhythmias. Heart Rhythm. 2016, 13, 311-320, doi:10.1016/j.hrthm.2015.08.016.

42. Babakr, A.A.; Fomison-Nurse, I.C.; van Hout, I.; Aitken-Buck, H.M.; Sugunesegran, R.; Davis, P.J.; Bunton, R.W.; Williams, M.J.A.; Coffey, S.; Stiles, M.K.; et al. Acute interaction between human epicardial adipose tissue and human atrial myocardium induces arrhythmic susceptibility. Am. J. Physiol. Endocrinol. Metab. 2020, 318, E164-E172, doi:10.1152/ajpendo.00374.2019.

43. Saremi, F.; Muresian, H.; Sánchez-Quintana, D. Coronary veins: Comprehensive CTanatomic classification and review of variants and clinical implications.Radiographics 2012, 32, E1-E32, doi:10.1148/rg.321115014.

44. Liang, J.J.; Bogun, F. Coronary Venous Mapping and Catheter Ablation for Ventricular Arrhythmias. Methodist Debakey Cardiovasc. J. 2021, 17, 13-18, doi:10.14797/HUZR1007.

45. Sirajuddin, A.; Chen, M.Y.; White, C.S.; Arai, A.E.; Coronary venous anatomy and anomalies. J. Cardiovasc. Comput. Tomogr. 2020, 14, 80-86, doi:10.1016/j.jcct.2019.08.006.

46. Briceño, D.F.; Enriquez, A.; Liang, J.J.; Shirai, Y.; Santangeli, P.; Guandalini, G.; Supple, G.E.; Schaller, R.; Arkles, J.; Frankel, D.S.; et al. Septal Coronary Venous Mapping to Guide Substrate Characterization and Ablation of Intramural Septal Ventricular Arrhythmia. JACC Clin. Electrophysiol. 2019, 5, 789-800, doi:10.1016/j.jacep.2019.04.011.

47. Alam, M.; Dokainish, H.; Lakkis, N. Alcohol septal ablation for hypertrophic obstructive cardiomyopathy: A systematic review of published studies. J. Interv. Cardiol. 2006, 19, 319-327, doi:10.1111/j.15408183.2006.00153.x.

48. Betensky, B.P.; Kapa, S.; Desjardins, B.; Garcia, F.C.; Callans, D.J.; Dixit, S.; Frankel, D.S.; Hutchinson, M.D.; Supple, G.E.; Zado, E.S.; et al. Characterization of trans-septal activation during septal pacing: Criteria for identification of intramural ventricular tachycardia substrate in nonischemic cardiomyopathy. Circ. Arrhythmia Electrophysiol. 2013, 6, 1123-1130, doi:10.1161/CIRCEP.113.000682.

49. Pothineni, N.V.K.; Garcia, F.C.; Santangeli, P. Radiofrequency Ablation Strategies for Intramural Ventricular Arrhythmias. Methodist Debakey Cardiovasc. J.2021, 17, 8-12, doi:10.14797/PEYF3776.

50. Ortale, J.R.; Marquez, C.Q. Anatomy of the intramural venous sinuses of the right atrium and their tributaries. Surg. Radiol. Anat. 1998, 20, 23-29, doi:10.1007/BF01628111.

51. Komatsu, Y.; Nogami, A.; Shinoda, Y.; Masuda, K.; Machino. T.; Kuroki, K.; Yamasaki, H.; Sekiguchi, Y.; Aonuma, K. Idiopathic Ventricular Arrhythmias Originating From the Vicinity of the Communicating Vein of Cardiac Venous Systems at the Left Ventricular Summit. Circ. Arrhythmia Electrophysiol. 2018, 11, e005386, doi:10.1161/CIRCEP.117.005386.

52. Wink, J.; van Delft, R.; Notenboom, R.G.E.; Wouters, P.F.; DeRuiter, M.C.; Plevier, J.W.M.; Jongbloed, M.R.M. Human adult cardiac autonomic innervation: Controversies in anatomical knowledge and relevance for cardiac neuromodulation. Auton. Neurosci. 2020, 227, 102674, doi:10.1016/j.autneu.2020.102674. 
53. Wallis, D.; Watson, A.H.; Mo, N. Cardiac neurones of autonomic ganglia. Microsc. Res. Tech. 1996, 35, 69-79, doi:10.1002/(SICI)1097-0029(19960901)35:1<69::AID-JEMT6>3.0.CO;2-N.

54. Kawashima, T. The autonomic nervous system of the human heart with special reference to its origin, course, and peripheral distribution. Anat. Embryol. 2005, 209, 425-438, doi:10.1007/s00429-005-0462-1.

55. Saburkina, I.; Rysevaite, K.; Pauziene, N.; Mischke, K.; Schauerte. P.; Jalife, J.; Pauza, D.H. Epicardial neural ganglionated plexus of ovine heart: Anatomic basis for experimental cardiac electrophysiology and nerve protective cardiac surgery. Heart Rhythm. 2010, 7, 942-950, doi:10.1016/j.hrthm.2010.02.036.

56. Spach, M.S.; Huang, S.; Armstrong, S.I.; Canent, R.V. Jr. Demonstration of peripheral conduction system in human hearts. Circulation 1963, 28, 333-338, doi:10.1161/01.cir.28.3.333.

57. Elizari, M.V. Fascicular Blocks: Update 2019. Curr. Cardiol. Rev. 2021, 17, 31-40, doi:10.2174/1573403X16666200708111928.

58. Elizari, M.V. Acunzo RS, Ferreiro, M. Hemiblocks revisited. Circulation 2007, 115, 1154-1163, doi:10.1161/CIRCULATIONAHA.106.637389.

59. Elizari, M.V. The normal variants in the left bundle branch system. J. Electrocardiol. 2017, 50, 389-399, doi:10.1016/j.jelectrocard.2017.03.004.

60. Pérez-Riera, A.R.; Baranchuk, A. Unusual conduction disorder: Left posterior fascicular block + left septal fascicular block. Ann. Noninvasive Electrocardiol. 2015, 20, 187-188, doi:10.1111/anec.12185.

61. Chen, S.; Lu, X.; Peng, S.; Xue, Y.; Zhou, G.; Ling, Z.; Wei, Y.; Yang, K.; Fu, W.; Cai, L.; et al. Ablation at Right Coronary Cusp as an Alternative and Favorable Approach to Eliminate Premature Ventricular Complexes Originating From the Proximal Left Anterior Fascicle. Circ. Arrhythmia Electrophysiol. 2020, 13, e008173, doi:10.1161/CIRCEP.119.008173; Erratum in 2020, 13,e000073.

62. Ito, S.; Tada, H.; Naito, S.; Kurosaki, K.; Ueda, M.; Hoshizaki, H.; Miyamori, I.; Oshima, S.; Taniguchi, K.; Nogami, A. Development and validation of an ECG algorithm for identifying the optimal ablation site for idiopathic ventricular outflow tract tachycardia. J. Cardiovasc. Electrophysiol. 2003, 14, 1280-1286, doi:10.1046/j.1540-8167.2003.03211.x.

63. Andrade, F.M.; Ribeiro, D.C.; Babinski, M.A.; Cisne, R.; Goes, M.L.; Triangle of Brocq and Mouchet: Anatomical study in brazilian cadavers and clinical implications. J. Morphol. Sci. 2010, 27, 3-4.

64. Agarwal, J.; Agrawal, A.;Sinha, D.N.; Virendra. Study of BROCQ and Mouchet triangles in human hearts-A cadaveric study and its clinical implication. IP Indian J. Anat. Surg. Head Neck Brain 2020, 6, 36-39. doi:10.18231/j.ijashnb.2020.011.

65. Dubey, A. Triangle of brocq and mouchet: An anatomicals in human cadaveric heart and its clinical significance. Int. J. Anat. Res. 2016, 4, 2266-2268. ISSN 2321-4287 doi:10.16965/ijar.2016.192.

66. Brocq, P.; Mouchet, A. Etude Anatomique Des Artères Coronaires Du Cœur; Maloine et fils: Paris, French, 1920.

67. Mandarim-De-Lacerda, C.A. Anatomia Do Coracao: Clinica e Cirurgica; Revinter: Rio de Janeiro, Brasil, 1990.

68. Benhayon, D.; Cogan, J.; Young, M. Left atrial appendage as a vantage point for mapping and ablating premature ventricular contractions originating in the epicardial left ventricular summit. Clin. Case Rep. 2018, 6, 1124-1127, doi:10.1002/ccr3.1525.

69. Altmann, D.R.; Knecht, S.; Sticherling, C.; Ammann, P.; Osswald, S.; Kühne, M. Ventricular tachycardia originating from the "Bermuda Triangle." Cardiovasc. Med. 2013, 16, 208-210. 
70. Yakubov, A.; Salayev, O.; Hamrayev, R.; Sultankhonov, S. A case of successful ablation of ventricular tachycardia focus in the left ventricular summit through the left atrial appendage: A case report. Eur. Heart J. Case Rep. 2018, 2, yty110, doi:10.1093/ehjcr/yty110.

71. Marai, I.; Boulos, M.; Lessick, J.; Abadi, S.; Blich, M.; Suleiman, M. Outflow tract ventricular arrhythmia originating from the aortic cusps: Our approach for challenging ablation. J. Interv. Card. Electrophysiol. 2016, 45, 57-62, doi:10.1007/s10840-015-0076-3.

72. Daniels, D.V.; Lu, Y.Y.; Morton, J.B.; Santucci, P.A.; Akar, J.G.; Green, A.; Wilber, D.J. Idiopathic epicardial left ventricular tachycardia originating remote from the sinus of Valsalva: Electrophysiological characteristics, catheter ablation, and identification from the 12-lead electrocardiogram. Circulation 2006,113, 1659-1666, doi:10.1161/CIRCULATIONAHA.105.611640.

73. Kumagai, K.; Fukuda, K.; Wakayama, Y.; Sugai, Y.; Hirose, M.; Yamaguchi, N.; Takase, K.; Yamauchi, Y.; Takahashi, A.; Aonuma, K.; et al. Electrocardiographic characteristics of the variants of idiopathic left ventricular outflow tract ventricular tachyarrhythmias. J. Cardiovasc. Electrophysiol. 2008, 19, 495-501, doi:10.1111/j.1540-8167.2007.01085.x.

74. Hayashi, T.; Santangeli, P.; Pathak, R.K.; Muser, D.; Liang, J.J.; Castro, S.A.; Garcia, F.C.; Hutchinson, M.D.; Supple, G.E.; Frankel, D.S.; et al. Outcomes of Catheter Ablation of Idiopathic Outflow Tract Ventricular Arrhythmias With an R Wave Pattern Break in Lead V2: A Distinct Clinical Entity. J. Cardiovasc. Electrophysiol. 2017, 28, 504-514, doi:10.1111/jce.13183.

75. Yamada, T.; McElderry, H.T.; Doppalapudi, H.; Murakami, Y.; Yoshida, Y.; Yoshida, N.; Okada, T.; Tsuboi, N.; Inden, Y.; Murohara, T.; et al. Idiopathic ventricular arrhythmias originating from the aortic root prevalence, electrocardiographic and electrophysiologic characteristics, and results of radiofrequency catheter ablation. J. Am. Coll. Cardiol. 2008, 52, 139-147, doi:10.1016/j.jacc.2008.03.040.

76. Stavrakis, S.; Jackman, W.M.; Nakagawa, H.; Sun, Y.; Xu, Q.; Beckman, K.J.; Lockwood, D.; Scherlag, B.J.; Lazzara, R.; Po, S.S. Risk of coronary artery injury with radiofrequency ablation and cryoablation of epicardial posteroseptal accessory pathways within the coronary venous system. Circ. Arrhythmia Electrophysiol. 2014, 7, 113-119, doi:10.1161/CIRCEP.113.000986.

77. Aoyama, H.; Nakagawa, H.; Pitha, J.V.; Khammar, G.S.; Chandrasekaran, K.; Matsudaira, K.; Yagi, T.; Yokoyama, K.; Lazzara, R.; Jackman, W.M. Comparison of cryothermia and radiofrequency current in safety and efficacy of catheter ablation within the canine coronary sinus close to the left circumflex coronary artery. J. Cardiovasc Electrophysiol. 2005, 16, 1218-1226.

78. Paul, T.; Bökenkamp, R.; Mahnert, B.; Trappe, H.J. Coronary artery involvement early and late after radiofrequency current application in young pigs. Am. Heart J. 1997, 133, 436-440.

79. Makimoto, H.; Zhang, Q.; Tilz, R.R.; Wissner, E.; Cuneo, A.; Kuck, K.H.; Ouyang, F. Aborted sudden cardiac death due to radiofrequency ablation within the coronary sinus and subsequent total occlusion of the circumflex artery. J. Cardiovasc. Electrophysiol. 2013, 24, 929-932.

80. Alazard, M.; Lacotte, J.; Horvilleur, J.; Ait-Said, M.; Salerno, F.; Manenti, V.; Piechaud, J.F.; Garot, J.; Bonnet, D.; Maltret, A.; Prventing the risk of coronary injury in posteroseptal accessory pathway ablation in children: Different strategies and advantages of fluoroscopy integrated 3D-mapping system (CARTOUNIVU). J. Interv. Card. Electrophysiol. 2018, 52, 127-135, doi:10.1007/s10840-018-0339-x.

81. Correia, M.; Maresca, D.; Goudot, G.; Villemain, O.; Bize, A.; Sambin, L.; Tanter, M.; Ghaleh, B.; Pernot, M. Quantitative imaging of coronary flows using 3D ultrafast Doppler coronary angiography. Phys. Med. Biol. 2020, 65, 105013, doi:10.1088/1361-6560/ab8d78.

82. Karkowski, G.; Kuniewicz, M.; Kozluk, E.; Chyzy, T.; Zabek, A.; Dusza, M.; Lelakowski, J. Nonfluoroscopic radiofrequency catheter ablation of right- and left-sided ventricular arrhythmias. Postepy Kardiol. Interwencyjnej 2020, 16, 321-329, doi:10.5114/aic.2020.99268. 
83. Igarashi, M.; Nogami, A.; Fukamizu, S.; Sekiguchi, Y.; Nitta, J.; Sakamoto, N.; Sakamoto, Y.; Kurosaki, K.; Takahashi, Y.; Kimata, A.; et al. Acute and long-term results of bipolar radiofrequency catheter ablation of refractory ventricular arrhythmias of deep intramural origin. Heart Rhythm. 2020, 17, 1500-1507, doi:10.1016/j.hrthm.2020.04.028.

84. Santangeli, P.; Marchlinski, F.E.; Zado, E.S.; Benhayon, D.; Hutchinson, M.D.; Lin, D.; Frankel, D.S.; Riley, M.P.; Supple, G.E.; Garcia, F.C.; et al. Percutaneous epicardial ablation of ventricular arrhythmias arising from the left ventricular summit: Outcomes and electrocardiogram correlates of success. Circ. Arrhythmia Electrophysiol. 2015, 8, 337-343, doi:10.1161/CIRCEP.114.002377.

85. Sacher, F.; Roberts-Thomson, K.; Maury, P.; Tedrow, U.; Nault, I.; Steven, D.; Hocini, M.; Koplan, B.; Leroux, L.; Derval, N.; et al. Epicardial ventricular tachycardia ablation a multicenter safety study. $J$. Am. Coll. Cardiol. 2010, 55, 2366-2372, doi:10.1016/j.jacc.2009.10.084.

86. Yamada, T.; Maddox, W.R.; McElderry, H.T.; Doppalapudi, H.; Plumb, V.J.; Kay, G.N. Radiofrequency catheter ablation of idiopathic ventricular arrhythmias originating from intramural foci in the left ventricular outflow tract: Efficacy of sequential versus simultaneous unipolar catheter ablation. Circ. ArrhythmiaElectrophysiol. 2015, 8, 344-352, doi:10.1161/CIRCEP.114.002259.

87. Yamada, T.; Yoshida, N.; Doppalapudi, H.; Litovsky, S.H.; McElderry, H.T.; Kay, G.N. Efficacy of an Anatomical Approach in Radiofrequency Catheter Ablation of Idiopathic Ventricular Arrhythmias Originating from the Left Ventricular Outflow Tract. Circ. Arrhythmia Electrophysiol. 2017, 10, e004959, doi:10.1161/CIRCEP.116.004959.

88. Candemir, B.; Baskovski, E.; Duzen, V.; Coskun, F.; Vurgun, K.; Goksuluk, H.; Ozyuncu, N.; Kurklu, S.T.; Altin, T.; Akyurek, O.; et al. Late elimination of challenging idiopathic ventricular arrhythmias originating from left ventricular summit by anatomical ablation. Indian Pacing Electrophysiol. J. 2019, 19, $114-118$.

89. Chung, F.P.; Lin, C.Y.; Shirai, Y.; Futyma, P.; Santangeli, P.; Lin, Y.J.; Chang, S.L.; Lo, L.W.; Hu, Y.F.; Chang, H.Y.; et al. Outcomes of catheter ablation of ventricular arrhythmia originating from the left ventricular summit: A multicenter study. Heart Rhythm. 2020, 17, 1077-1083, doi:10.1016/j.hrthm.2020.02.02.

90. Aly, I.; Rizvi, A.; Roberts, W.; Khalid, S.; W. Kassem, M.W.; Salandy, S.; du Plessis, M.; Tubbs, R.S.; Loukas, M. Cardiac ultrasound: An Anatomical and Clinical Review. Transl. Res. Anat. 2021, 22, 100083, ISSN 2214-854X, doi:10.1016/j.tria.2020.100083.

91. Nogami, A. Behind the Valsalva: What Else Is Hiding? Circ. Arrhythmia Electrophysiol. 2020, 13, e008611, doi:10.1161/CIRCEP.120.008611.

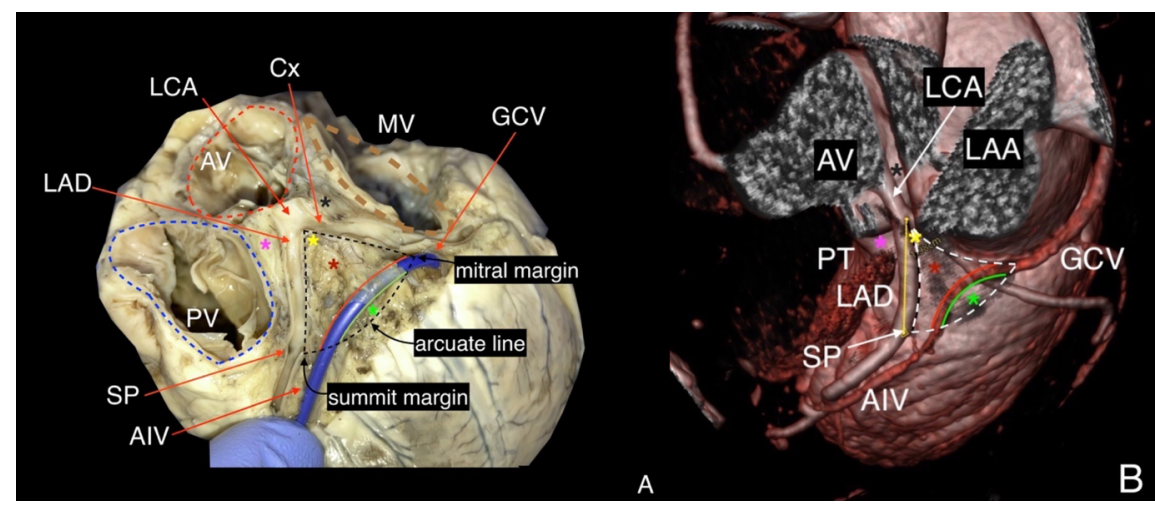



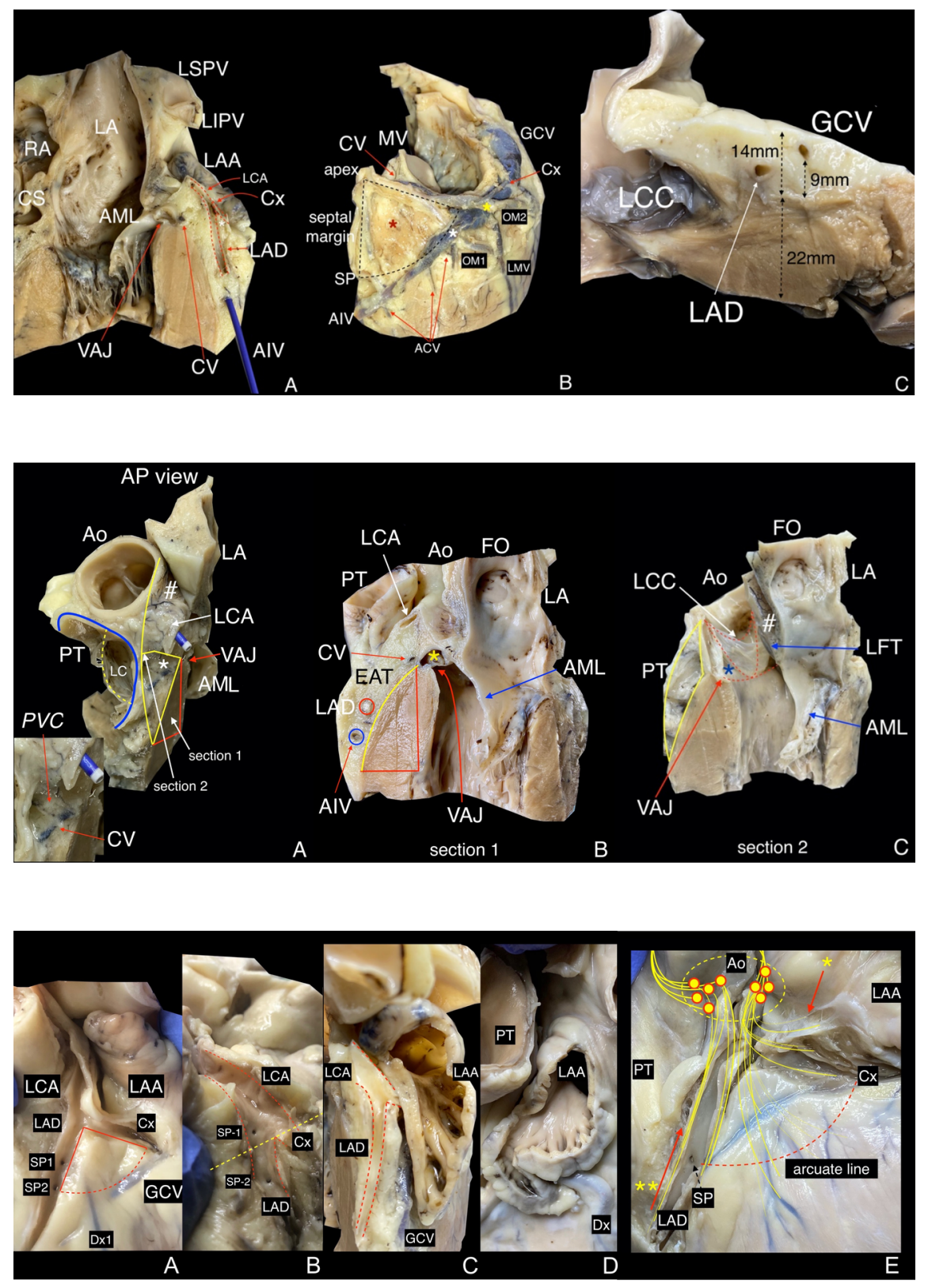